\title{
A small molecule compound with an indole moiety inhibits the main protease of SARS-CoV-2 and blocks virus replication
}

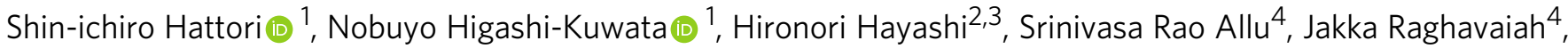
Haydar Bulut (10) ${ }^{5}$, Debananda Das (D) ${ }^{5}$, Brandon J. Anson (1) 6, Emma K. Lendy ${ }^{6}$, Yuki Takamatsu (1) ${ }^{1}$, Nobutoki Takamune7, Naoki Kishimoto (i) ${ }^{8}$, Kazutaka Murayama9 , Kazuya Hasegawa ${ }^{10}$, Mi Li $^{11,12}$, David A. Davis ${ }^{13}$, Eiichi N. Kodama ${ }^{3,14}$, Robert Yarchoan (1) ${ }^{13}$, Alexander Wlodawer (i) ${ }^{11}$, Shogo Misumi (D) ${ }^{8}$, Andrew D. Mesecar ${ }^{6}$, Arun K. Ghosh ${ }^{4}$ \& Hiroaki Mitsuya (10 1,5,15凶

Except remdesivir, no specific antivirals for SARS-CoV-2 infection are currently available. Here, we characterize two small-molecule-compounds, named GRL-1720 and 5h, containing an indoline and indole moiety, respectively, which target the SARS-CoV-2 main protease (Mpro). We use VeroE6 cell-based assays with RNA-qPCR, cytopathic assays, and immunocytochemistry and show both compounds to block the infectivity of SARS-CoV-2 with EC 50 values of $15 \pm 4$ and $4.2 \pm 0.7 \mu \mathrm{M}$ for GRL-1720 and 5h, respectively. Remdesivir permitted viral breakthrough at high concentrations; however, compound $5 \mathrm{~h}$ completely blocks SARSCoV-2 infection in vitro without viral breakthrough or detectable cytotoxicity. Combination of $5 \mathrm{~h}$ and remdesivir exhibits synergism against SARS-CoV-2. Additional X-ray structural analysis show that $5 \mathrm{~h}$ forms a covalent bond with $\mathrm{M}^{\mathrm{pro}}$ and makes polar interactions with multiple active site amino acid residues. The present data suggest that $5 \mathrm{~h}$ might serve as a lead Mpro inhibitor for the development of therapeutics for SARS-CoV-2 infection.

\footnotetext{
${ }^{1}$ Department of Refractory Viral Infections, National Center for Global Health and Medicine Research Institute, Tokyo, Japan. ${ }^{2}$ Department of Intelligent Network for Infection Control, Tohoku University Hospital, Miyagi, Japan. ${ }^{3}$ Department of infectious Diseases, International Research Institute of Disaster Science, Tohoku University, Miyagi, Japan. ${ }^{4}$ Department of Chemistry and Department of Medicinal Chemistry and Molecular Pharmacology, Purdue University, West Lafayette, IN, USA. ${ }^{5}$ Experimental Retrovirology Section, HIV and AIDS Malignancy Branch, National Cancer Institute, National Institutes of Health, Bethesda, MD, USA. ${ }^{6}$ Department of Biochemistry and Department of Biological Sciences, Purdue University, West Lafayette, IN, USA. ${ }^{7}$ Kumamoto Innovative Development Organization, Kumamoto University, Kumamoto, Japan. ${ }^{8}$ Department of Environmental and Molecular Health Sciences, Faculty of Medical and Pharmaceutical Sciences, Kumamoto University, Kumamoto, Japan. ${ }^{9}$ Graduate School of Biomedical Engineering, Tohoku University,

Miyagi, Japan. ${ }^{10}$ Protein Crystal Analysis Division, Japan Synchrotron Radiation Research Institute, Hyogo, Japan. ${ }^{11}$ Protein Structure Section, Center for Structural Biology, National Cancer Institute, Frederick, MD, USA. ${ }^{12}$ Basic Science Program, Leidos Biomedical Research, Frederick National Laboratory for Cancer Research, Frederick, MD, USA. ${ }^{13}$ Viral Oncology Section, HIV and AIDS Malignancy Branch, National Cancer Institute, National Institutes of Health, Bethesda, MD, USA. ${ }^{14}$ Department of Infectious Diseases, Graduate School of Medicine and Tohoku Medical Megabank Organization, Tohoku University, Miyagi, Japan. ${ }^{15}$ Department of Clinical Sciences, Kumamoto University Hospital, Kumamoto, Japan. ${ }^{凶}$ email: hmitsuya@hosp.ncgm.go.jp
} 
T he novel coronavirus disease 2019 (COVID-19) caused by a positive-strand RNA virus, severe acute respiratory syndrome coronavirus 2 (SARS-CoV-2), started in Wuhan, Hubei province, China ${ }^{1-4}$ and escalated into the pandemic. As of December 14, 2020, more than 71 million COVID-19 cases have been reported in 220 countries and more than 1.6 million deaths ${ }^{5}$. Currently, except for remdesivir, which was most recently approved as the first proven emergency therapeutic for treating COVID-19, no specific therapeutics are available. The hope that the COVID-19 pandemic subsides with "herd immunity" is likely to be disappointing. Moreover, it is not clear whether COVID-19convalescent people with antibodies to SARS-CoV-2 are immune to reinfection. It is of utmost urgency to develop effective antivirals, therapeutics that mitigate the lethal consequences of cytokine storm and effective vaccines.

An efficient approach to drug discovery to a pathogenic agent includes the examination of existing compounds that are known to be active against related pathogens and the ensuing optimization of lead compounds. SARS-CoV-2, which causes COVID19 , belongs to the family of betacoronaviruses that includes SARS-CoV and MERS-CoV. The genome of SARS-CoV-2 has overall $\sim 80 \%$ nucleotide identity with that of SARS- $\mathrm{CoV}^{6}$ and the main proteases $\left(\mathrm{M}^{\mathrm{Pro}}\right)$ of these two viruses have $96 \%$ amino acid sequence identity (Fig. 1a). Superimposition of the structures of the $M^{\text {pro }}$ of both SARS-CoV-2 and SARS-CoV shows near identity in their tertiary structures (Fig. 1b-d). a

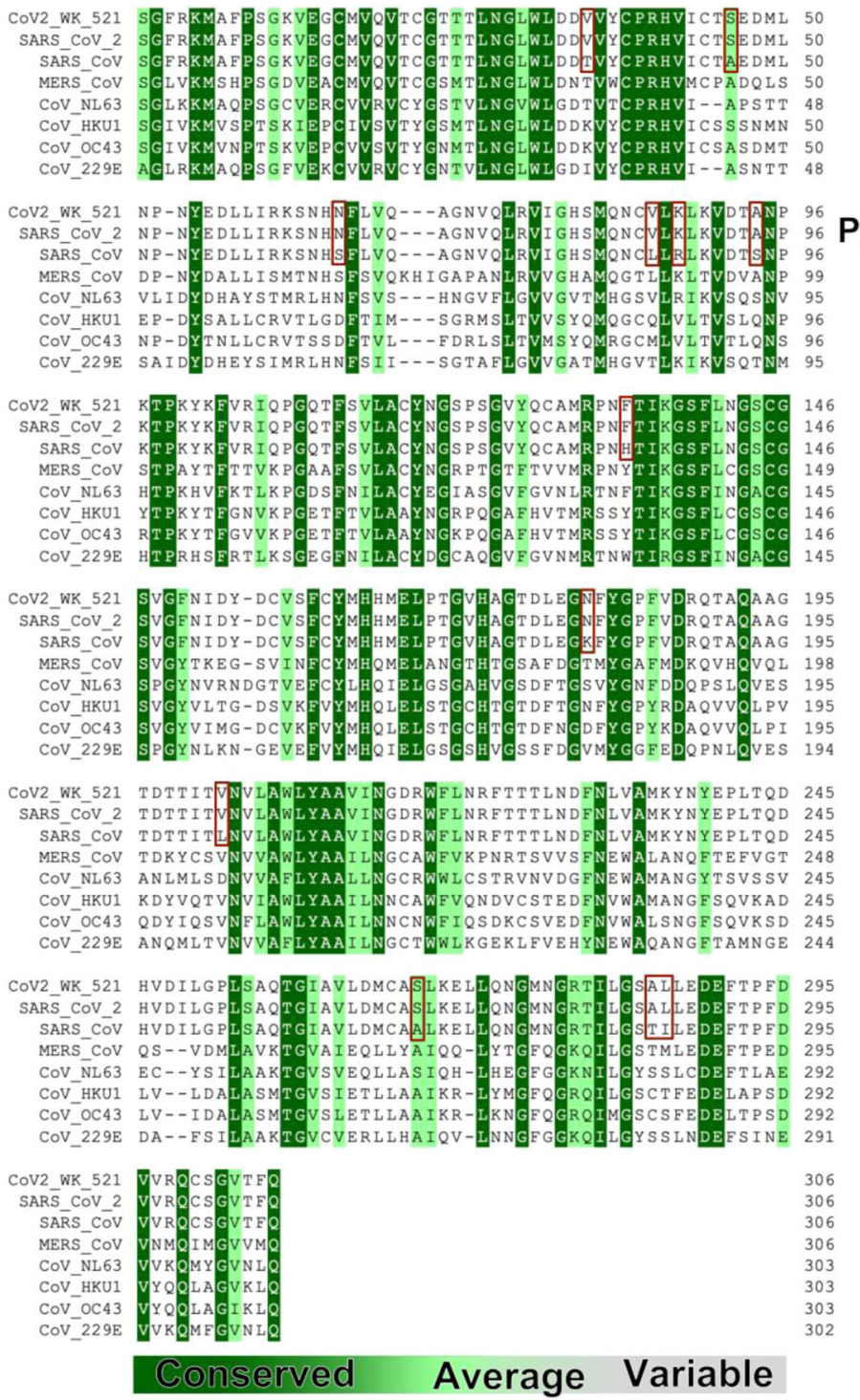

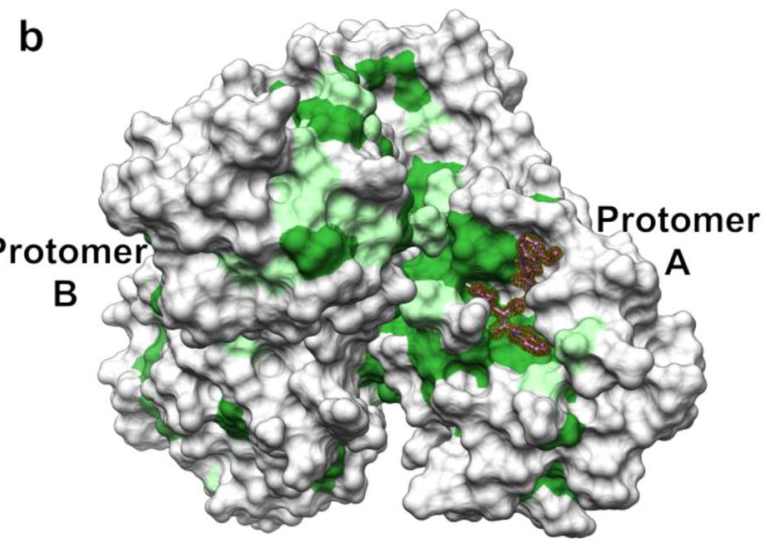
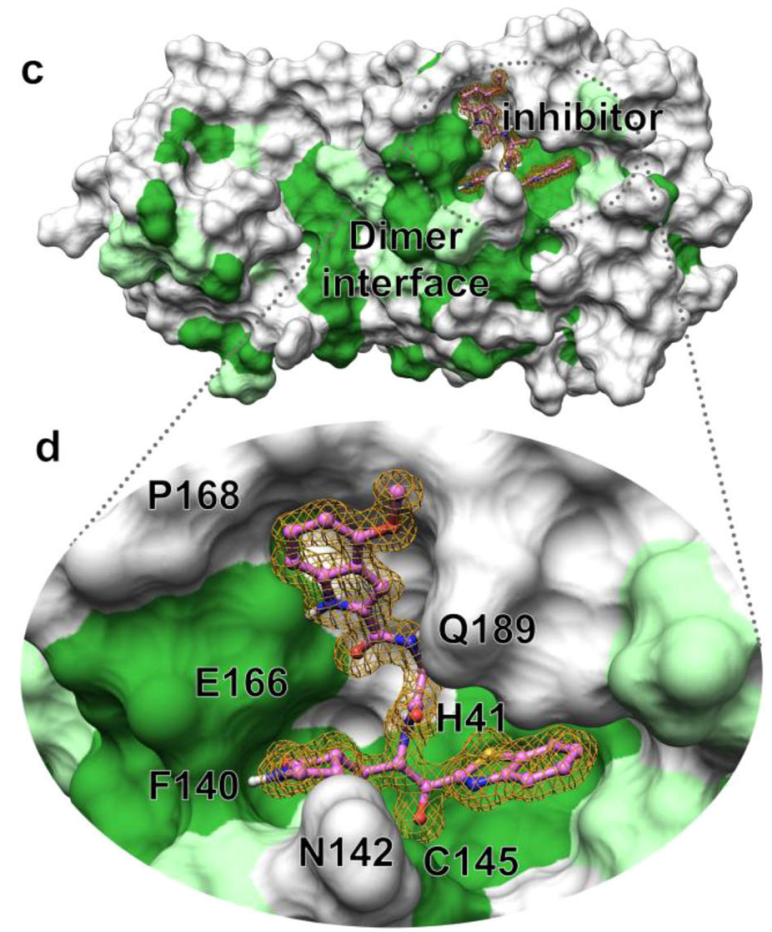

Fig. 1 Human coronaviruses Main proteases ( $\mathbf{M}^{\text {pros}} \mathbf{s}$ ) are highly conserved around the dimer interface and ligand binding groove. a Amino acid sequence alignment of main proteases ( $\mathrm{M}^{\text {pros}} \mathrm{S}$ ) of eight human coronaviruses are shown. Identical amino acids are indicated in dark green; moderately conserved residues in light green and variable amino acids in light gray. The sequence of Mpro of SARS-CoV- $2^{\text {WK- } 521}$ used in the present study is completely identical to that of SARS-CoV-2 (PDB:6LU7) and shares $96 \%$ identity with the SARS-CoV (PDB: 2 AMQ). The 12 amino acid residues that differ between the sequence of SARS-CoV's Mpro and that of SARS-CoV-2WK-521 are highlighted in pink. Other less conserved sequences are from Mpros of MERS-CoV (PDB: 5C3N), CoV-NL63 (PDB: 5GWY), CoV-HKU1 (PDB: 3D23), CoV-229E (PDB: 2ZU2) and CoV-OC43 (Uniprot: P0C6X6). Sequence alignment was performed using Multiple Align Show (http://www.bioinformatics.org/SMS/multi_align.html). b Conservation of each residue is mapped onto the surface of Mpro structure based on the sequence alignment shown in (a). c While $\mathrm{M}^{\mathrm{pro}} \mathrm{s}$ exhibit a high sequence conservation around the dimer interface in the center part of each protomer, the external part of each protomer shows high variability. d Omitted electron density (2Fo-Fc) of 5 h, contoured at the $1 \sigma$ level is shown inside the binding groove. 5h targets mainly a conserved site. 
Structurally, the 5' two-thirds of the viral genome encodes two overlapping polyproteins, ppla and pplab, which are processed to generate the viral replication complex, replicase polyprotein, which undergoes processing by two viral proteases, the Mpro and papainlike protease $\left(\mathrm{PL}^{\mathrm{pro}}\right)^{7-11}$. The role of the two proteases is essential for the replication of SARS-CoV and both proteases have been recognized as attractive targets for developing antiviral agents ${ }^{12-15}$. Based on the high structural homology, we examined potential activity of experimental Mpro inhibitors, which had been shown to be active against SARS-CoV ${ }^{16-19}$, against a newly isolated SARS-CoV-2 strain, JPN/TY/WK-521 (SARS-CoV-2WK-521), in VeroE6 cell-based assay employing RNA-qPCR assay, cytopathicity assays, and immunocytochemistry. Indeed, the Mpro of SARS-CoV-2WK-521 (PDB: 6XR3) proved to have the same amino acid sequence identity with the Mpro of SARS-CoV-2 (PDB:6LU7) (Fig. 1a). Here, we demonstrated that two compounds, GRL-1720 and compound $5 \mathrm{~h}^{20}$, containing an indoline and indole moiety, respectively, potently block the infectivity of SARS-CoV-2 by targeting Mpro. Importantly, 5h blocked the infectivity and cytopathicity of the virus with high potency and without any detectable cytotoxicity even at $200 \mu \mathrm{M}$, as examined using detailed immunocytochemistry.

\section{Results}

GRL-1720 and compound 5 h potently block the infectivity and cytopathicity of SARS-CoV-2WK-521. We have examined a variety of compounds that have reportedly been active against SARS-CoV 21 . We specifically selected and synthesized a panel of active compounds based on previously known structures and their activity against SARS-CoV ${ }^{16-20}$. We demonstrated previously that two compounds, GRL-1720 (Supplementary Fig. 1) and 5h (Supplementary Fig. 2), potently inhibit Mpro from SARS-CoV and have anti-SARS-CoV activity ${ }^{16,20}$. They also potently block the enzymatic activity of SARS-CoV-2 Mpro and the infectivity, replication, and cytopathicity of SARS-CoV-2 $2^{\mathrm{WK}-521}$ (Fig. 2 and
Supplementary Fig. 3). GRL-1720 and 5h potently inhibited the enzymatic activity of SARS-CoV-2 Mpro. GRL-1720 is an irreversible, covalent inhibitor of SARS-CoV-2 Mpro with time-dependent inhibition kinetic parameters of $k_{\text {inact }}=2.53 \pm 0.27 \mathrm{~min}^{-1}, \mathrm{~K}_{\mathrm{i}}=$ $2.15 \pm 0.49 \mu \mathrm{M}$ and a second-order rate constant, $k_{\text {inact }} / \mathrm{K}_{\mathrm{i}}=$ $19,610 \mathrm{M}^{-1} \pm 4,930 \mathrm{sec}^{-1}$ (Supplementary Fig. 3a, b). The $\mathrm{IC}_{50}$ value for GRL-1720 after a $10 \mathrm{~min}$ incubation is $0.32 \pm 0.02 \mu \mathrm{M}$ (Supplementary Fig. 3c). 5h on the other hand is a tight-binding, reversible-covalent inhibitor of SARS-CoV-2 Mpro with a $\mathrm{K}_{\mathrm{i}}$ value of $17.6 \pm 3.2 \mathrm{nM}$ as determined using the Morrison equation (Supplementary Fig. 3d). As assessed using the quantitative VeroE6 cell-based assay with RNA-qPCR, the EC $_{50}$ values of GRL-1720 and compound $5 \mathrm{~h}$ were $15 \pm 4$ and $4.2 \pm 0.7 \mu \mathrm{M}$, respectively, and apparent $\mathrm{CC}_{50}$ values were both $>100 \mu \mathrm{M}$ (Fig. 2).

It is noteworthy that cell cytotoxicity of certain compounds reduces virion production by the cells and such reduction is often misinterpreted as antiviral activity of the compounds. For example, the anti-cancer/leukemia agent, daunorubicin (aka Adriamycin), was reported to be active against HIV-1 ${ }^{22,23}$, but that anti-cancer/leukemia agent never proved to be of clinical utility as an anti-HIV-1 agent. Thus, we carefully asked if the three compounds, GRL-1720, 5h, and remdesivir exerted cytotoxicity at 1,10 , and $100 \mu \mathrm{M}$. As seen in Fig. 3, VeroE6 cells cultured alone (top left in Fig. 3) appeared to be robust and had spread at the bottom of the microtiter culture plates; however, when VeroE6 cells were exposed to SARS-CoV-2WK-521 and cultured in the absence of test compounds, almost all the cells acquired granular patterns and became detached from the bottom of the culture plate (top right in Fig. 3), indicating the cells were infected and killed by the cytopathicity of the virus. In contrast, when the SARS-CoV-2 ${ }^{\mathrm{WK}-521}$-exposed cells were cultured in the presence of each of the three compounds (GRL-1720, 5h, and remdesivir) at $10 \mu \mathrm{M}$, the cells appeared to be moderately protected, and at $100 \mu \mathrm{M}$, all the cells appeared to be completely protected by each<smiles>O=C(Oc1cncc(Cl)c1)c1cccc2c1CCN2</smiles>

GRL-1720 $\mathrm{EC} 50=15 \pm 4 \mu \mathrm{M}$ CC50 $>100 \mu \mathrm{M}$

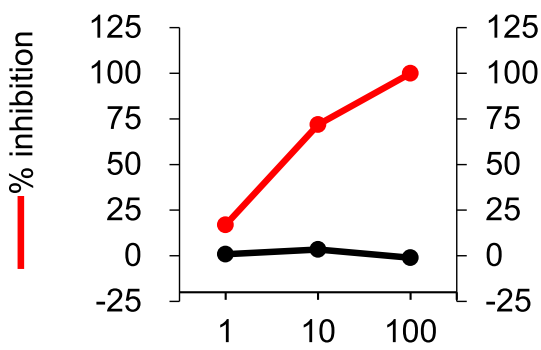<smiles>COc1cccc2[nH]c(C(=O)N[C@@H](CC(C)C)C(=O)N[C@@H](CC3CCNC3=O)C(=O)c3nc4ccccc4s3)cc12</smiles>

$5 \mathrm{~h}$

$$
\begin{gathered}
\mathrm{EC} 50=4.2 \pm 0.7 \mu \mathrm{M} \\
\mathrm{CC} 50>100 \mu \mathrm{M}
\end{gathered}
$$

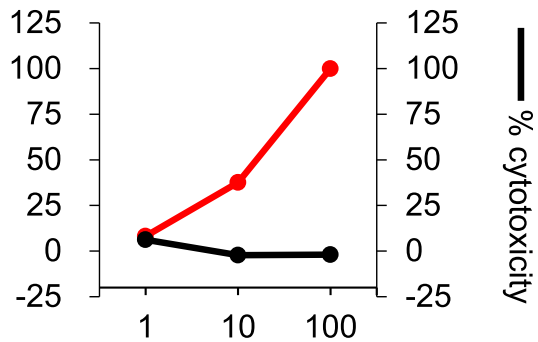

\section{Concentration $(\mu \mathrm{M})$}

Fig. $\mathbf{2}$ The antiviral activity of GRL-1720 and compound $\mathbf{5 h}$ against SARS-CoV-2. VeroE6 cells were exposed to SARS-CoVWK-521 for $1 \mathrm{~h}$, the virus was washed out, and the virus-exposed VeroE6 cells were cultured for 3 days. The viral copy numbers in the culture supernatants were determined using RT-qPCR. Red and black lines indicate reduction of viral copy numbers and cytotoxicity, respectively. Each compound was tested upon at least three different occasions. The data in Fig. 2 are representative ones. Both graphs were generated with Microsoft Excel. EC 50 values shown denote means \pm 1 S.D. All compounds shown in Fig. 2 were tested and compared in one assay performed in duplicate $(n=2)$. Source data are provided as a Source Data file. 


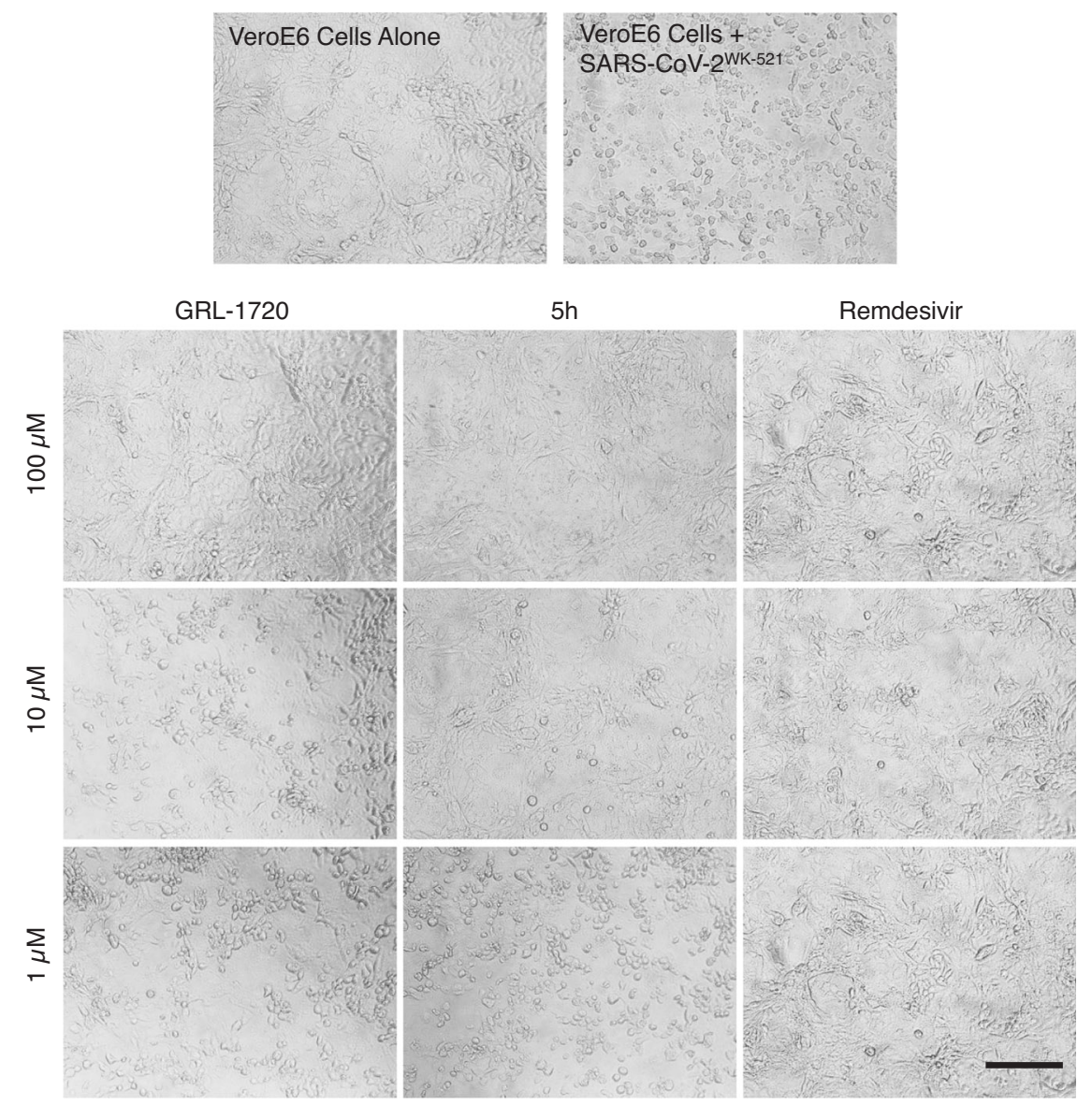

Fig. 3 GRL-1720 and 5h exert potent activity against SARS-CoV-2WK-521. VeroE6 cells were exposed to SARS-CoV-2 ${ }^{\text {WK-521 }}$ for $1 \mathrm{~h}$, the virus was washed off, and the cells were cultured in the presence of various concentrations of test compound for 3 days. The images shown are those captured under light microscopy. VeroE6 cells cultured alone (top left) appear to be robust; however, those exposed to SARS-CoV-2WK-521 and cultured in the absence of test compounds, a number of cells were destroyed by the cytopathicity of the virus and appear granular (top right). VeroE6 cells exposed to the virus and cultured with each of the two compounds, GRL-1720 and $5 \mathrm{~h}$ (at 1, 10 and $100 \mu \mathrm{M}$ ). The virus-exposed cells cultured with $100 \mu \mathrm{M}$, all the cells appeared to be completely protected. Representative images from three independent experiments are shown. Scale bar $=200 \mu \mathrm{m}$.

compound. All three images of the cells cultured with $100 \mu \mathrm{M}$ of each compound appeared to be similar to the image of the cells cultured without the virus (top left in Fig. 3). Moreover, 5h, at 200 $\mu \mathrm{M}$, showed no significant cytotoxicity in a human lung cancer cell line, Calu-3, or two human primary cells [peripheral blood mononuclear cells (PBMC) and human bronchial/tracheal epithelial cells (HBTEC)]. In contrast, remdesivir showed cytotoxicity at $200 \mu \mathrm{M}$ and its $\mathrm{CC}_{50}$ value was $138 \pm 9 \mu \mathrm{M}$ in HBTEC (Supplementary Table 1). When primary human airway epithelial cells were cultured in the air-liquid interface (ALI) setting in the presence of up to $100 \mu \mathrm{M}$ of $5 \mathrm{~h}$ and remdesivir, no detectable cytotoxicity was observed, although those cells were poorly susceptible to the infectivity of SARS-CoV-2 ${ }^{\text {WK- }-521}$ (Supplementary Fig. 4). These results strongly suggest that $5 \mathrm{~h}$ exerts its potent inhibitory activity against SARS-CoV-2 at concentrations that do not bring about detectable cytotoxicity.

GRL-1720 and $5 \mathrm{~h}$ are potent against SARS-CoV-2 ${ }^{\mathrm{WK}-521}$ as assessed with immunocytochemistry. In order to confirm and corroborate the potent antiviral activity of GRL-1720 and 5h observed using the quantitative RNA-qPCR assay, which often does not differentiate the actual antiviral activity from the misleading and distractive apparent "antiviral effect" caused by the cytostatic effect and/or cytotoxicity of test compounds, we employed immunocytochemistry, which can allow us to examine the antiviral activity of test compounds at the cellular level. For the primary antibody in our immunocytochemistry, we used an IgG fraction isolated from a COVID-19-convalescent patient, who proved to have high titers of neutralizing antibodies as well as SARS-CoV-2-binding IgG antibodies (Data not shown). As shown in Fig. 4, when VeroE6 cells were cultured alone, robust cellular cytoskeleton filamentous actin (F-actin) was seen as mesh-like structures (shown in red) and a number of nuclei (shown in blue) were identified, signifying that those cells were healthy and replicating (top left in Fig. 4). However, when VeroE6 cells were exposed to SARS-CoV-2 ${ }^{\mathrm{WK}-521}$ and cultured in the absence of test compound, the F-actin structure was lost and a number of cells were infected by the virus (stained in green; top right in Fig. 4). In contrast, in SARS-CoV-2 ${ }^{\mathrm{WK}-521}$-exposed VeroE6 cells that were cultured in the presence of $100 \mu \mathrm{M}$ GRL-1720, there was a significant reduction in the number of SARS-CoV-2 ${ }^{\mathrm{WK}-521}$-infected cells and there were essentially no infected cells when the cells were cultured in the presence of $100 \mu \mathrm{M}$ GRL-1720. In contrast, in the presence of as low as $10 \mu \mathrm{M} 5 \mathrm{~h}$, there was significant reduction in the number of infected cells and there were no infected cells when VeroE6 cells were cultured at $100 \mu \mathrm{M} 5 \mathrm{~h}$. Remdesivir also significantly reduced the number of infected cells at 10 and $100 \mu \mathrm{M}$; however, there was viral breakthrough in the culture and some infected cells were identified. The viral breakthrough in VeroE6 cell culture in the presence of remdesivir is shown in higher magnification in Supplementary Fig. 5. 

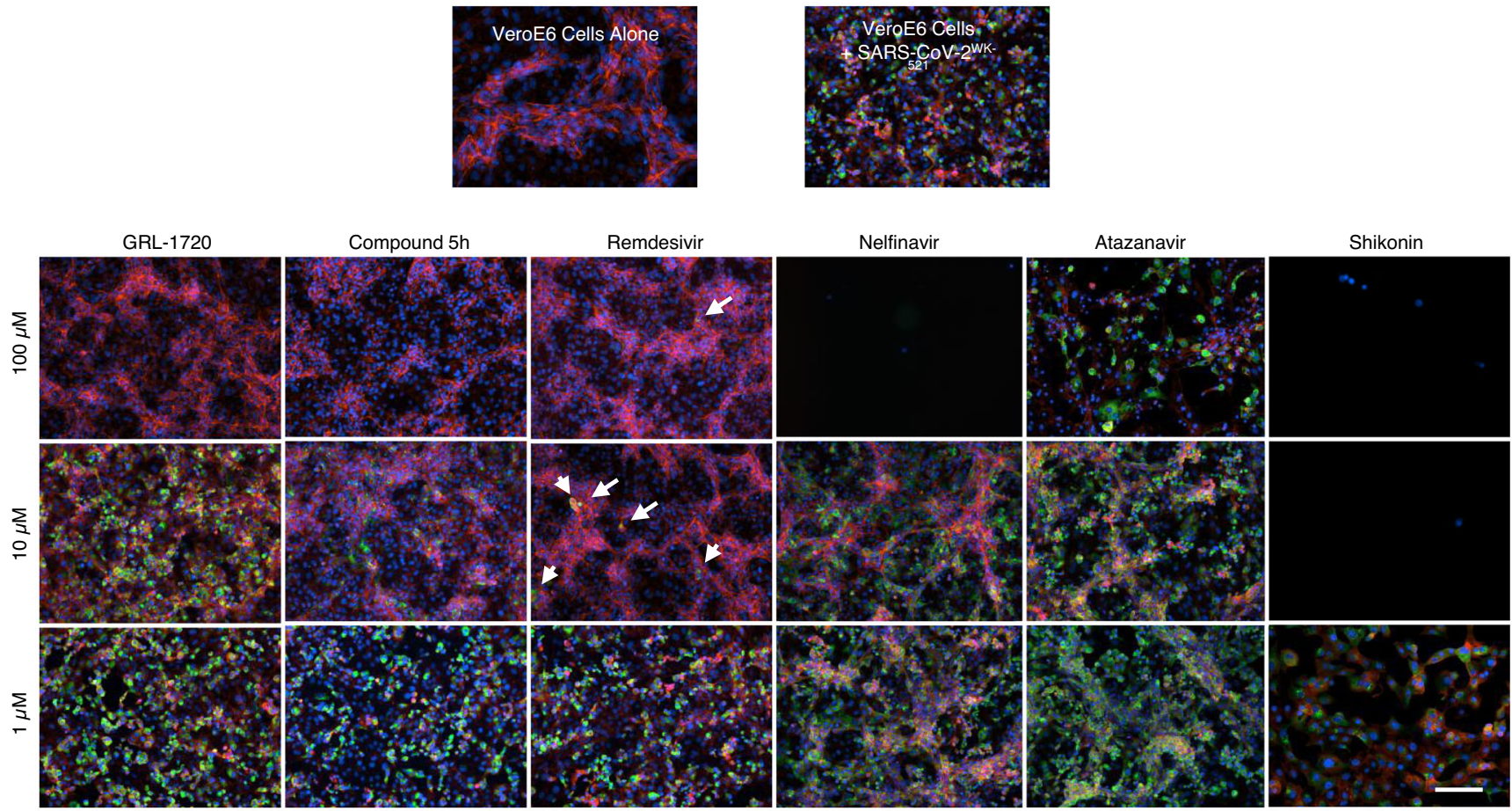

Fig. 4 GRL-1720 and 5h exert potent activity against SARS-CoV-2WK-521 but shikonin, nelfinavir, and atazanavir, reportedly active against SARS-CoV-2 failed to block the infection by SARS-CoV-2WK-521. VeroE6 cells were exposed to SARS-CoV-2WK-521 for $1 \mathrm{~h}$, the viruses were washed out, and the virusexposed cells were cultured in the presence or absence of various concentrations of each test compound for 3 days. Immunocytochemistry was then performed using an IgG fraction prepared from COVID-19-convalescent plasma as a primary antibody. Viral breakthrough was observed in the cells cultured in the presence of remdesivir at $100 \mu \mathrm{M}$, while in the cells cultured with $100 \mu \mathrm{M}$ GRL-1720 and 5h, no such virus breakthrough was found. Arrows denote the cells infected by the virus in the presence of high concentrations of remdesivir. Such breakthrough cells (stained in green) are often seen in clusters. SARS-CoV-2 antigens, F-actin, and nuclei are stained in green, red, and blue, respectively. Representative images from three independently conducted experiments are shown. Scale bar $=100 \mu \mathrm{m}$.

In order to further examine the antiviral activity of remdesivir, GRL-1720, and 5h, we tested the antiviral activity in SARS-CoV$2^{\text {WK-521 }}$-exposed VeroE6 cells that were cultured in the presence of a wide range of concentrations of each compound. In the set of immunocytochemistry data, there was no virus breakthrough in all of the fields examined using Cell Imaging Multi-Mode Reader (Cytation 5) at concentrations 50 through $100 \mu \mathrm{M}$; however, there were obvious virus breakthroughs at 150 and $200 \mu \mathrm{M}$ of remdesivir (Supplementary Fig. 6). In contrast, there was no virus breakthrough identified in the cells cultured in the presence of $5 \mathrm{~h}$ at concentrations ranging $20-200 \mu \mathrm{M}$ (Supplementary Fig. 6). Of note, while the amounts of F-actin appeared to have decreased at $100 \mu \mathrm{M}$ and higher concentrations of remdesivir, there was no significant decrease in the amounts of F-actin throughout the wide range of concentrations of $5 \mathrm{~h}$ tested, suggesting that $5 \mathrm{~h}$ is less cytotoxic than remdesivir (Supplementary Fig. 6 and Supplementary Table 1).

Shikonin was reported by Jin et al. ${ }^{24}$ to be well-docked into the putative hydrophobic cavity of Mpro's active site and shown by that group to exert activity against SARS-CoV-2; however, shikonin totally failed to block the infectivity of SARS-CoV-2 ${ }^{\mathrm{WK}-521}$ and was highly toxic even at $1 \mu \mathrm{M}$ (VeroE6 cells were swollen and apparently dying). At 10 and $100 \mu \mathrm{M}$, all the cells were presumably killed by the direct toxicity of shikonin as examined with detailed immunocytochemistry (Fig. 4). Two HIV-1 protease inhibitors, nelfinavir and atazanavir, which have also been reported to be active against SARS-CoV-2 ${ }^{25-27}$, did not show any detectable antiSARS-CoV-2 activity and, in our study, nelfinavir was highly toxic at $100 \mu \mathrm{M}$ (Fig. 4). These data strongly suggest that the apparent anti-SARS-CoV-2 effects of various compounds have been mistakenly interpreted as activity against the virus and that the cytostatic and cytotoxicity of such compounds are to be carefully examined.

Compound $5 \mathrm{~h}$ as combined with remdesivir exerts synergistic activity against SARS-CoV-2 and viral breakthrough does not occur. Remdesivir is a nucleotide analog that reportedly blocks the infectivity of SARS-CoV-2 through acting as an inhibitor of a viral RNA-dependent RNA polymerase (RdRp) ${ }^{28,29}$, whereas $5 \mathrm{~h}$ blocks the infectivity of the virus through acting as an Mpro inhibitor. Thus, we asked whether these two compounds work against SARS-CoV-2 in an additive or synergistic fashion in the VeroE6 cell-based assays (Fig. 5). The cells were exposed to SARS-CoV$2^{\mathrm{WK}-521}$ and cultured in the presence or absence of various concentrations of remdesivir in combination with various concentrations of $5 \mathrm{~h}$. Remdesivir $(2 \mu \mathrm{M})$ and compound $5 \mathrm{~h}(2 \mu \mathrm{M})$ suppressed the viral replication by 0.67 -fold (the geometric mean of viral RNA copy number was $3.4 \times 10^{10}$ with a range $3.1-3.6 \times$ $10^{10}$ copies $\left./ \mu \mathrm{L}\right)$ and 1.3 -fold $\left(1.8 \times 10^{10} ; 1.5-2.2 \times 10^{10}\right)$, respectively, while when the two compounds were combined, the suppression was by 1.8 -fold $\left(1.3 \times 10^{10} ; 1.2-1.4 \times 10^{10}\right)$. Remdesivir $(4 \mu \mathrm{M})$ and $5 \mathrm{~h}(4 \mu \mathrm{M})$ suppressed the viral replication by 0.53 -fold $\left(4.3 \times 10^{10} ; 3.9-4.7 \times 10^{10}\right)$ and 2.0 -fold $\left(1.1 \times 10^{10} ; 1.1-1.2 \times 10^{10}\right)$, respectively, while when combined, the suppression was by 24 -fold $\left(9.5 \times 10^{8} ; 8.3 \times 10^{8}-1.1 \times 10^{9}\right)$. At $10 \mu \mathrm{M}$, remdesivir and $5 \mathrm{~h}$ suppressed by 20 -fold $\left(1.2 \times 10^{10} ; 8.3 \times 10^{9}-1.6 \times 10^{10}\right)$ and 210 -fold $\left(1.1 \times 10^{8} ; 3.3 \times 10^{7}-3.3 \times 10^{8}\right)$, respectively, while, when combined, the suppression was by 590,000 -fold $\left(3.8 \times 10^{4}\right.$; 2.0-7.4 $\left.\times 10^{4}\right)$. The apparent combination effect was maximal 
a
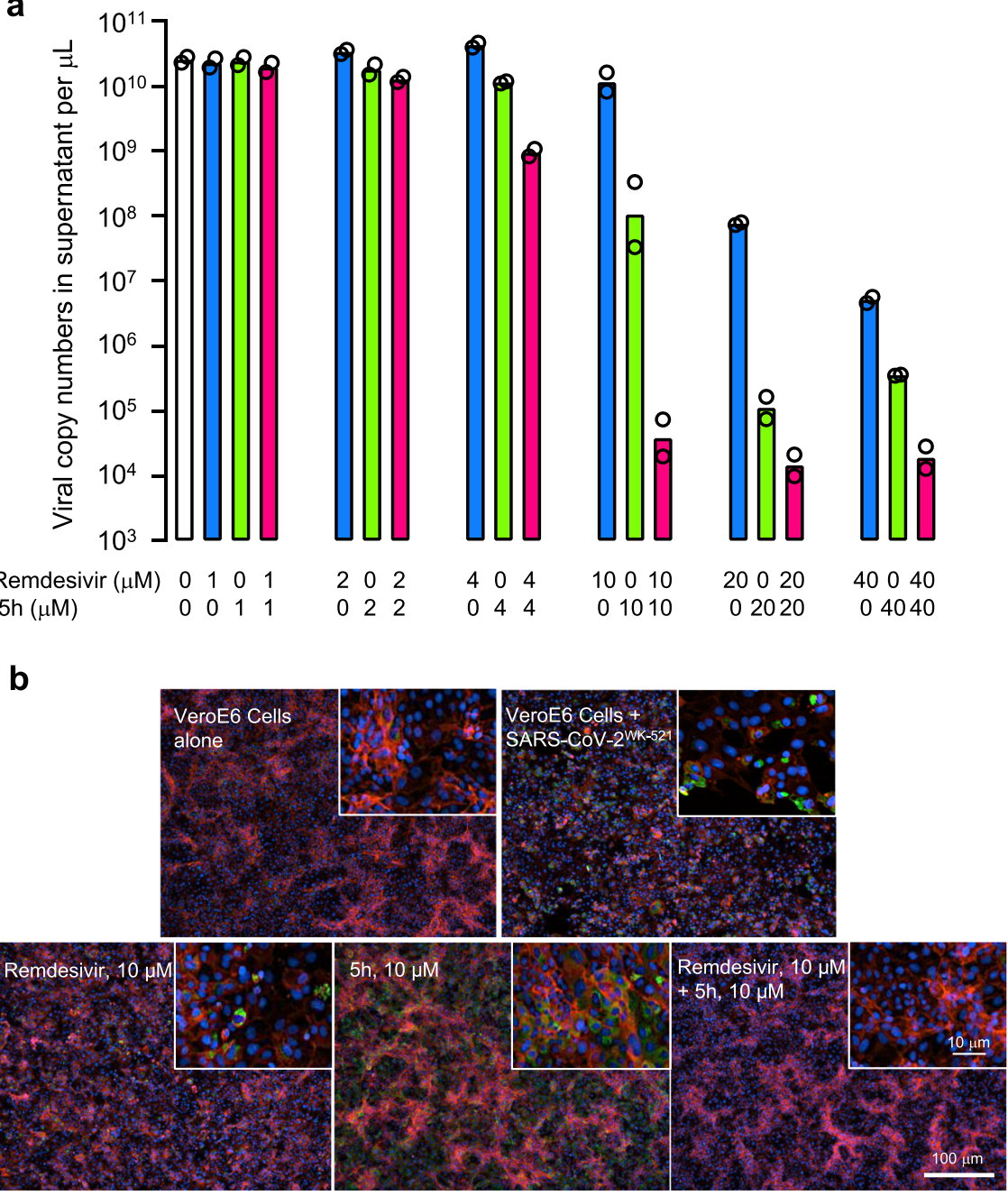

Fig. 5 Compound $\mathbf{5 h}$ combined with remdesivir does not permit viral breakthrough. VeroE6 cells were exposed with SARS-CoV-2WK-521 for $1 \mathrm{~h}$, the virus was washed out, and the virus-exposed cells were cultured for 3 days in the presence of compounds. a Viral RNA copy numbers in the culture supernatants were determined using RNA-qPCR. The numbers of viral RNA copy were more significantly reduced in the combination of $5 \mathrm{~h}$ and remdesivir (each at 4,10 , 20 , and $40 \mu \mathrm{M}$ ) than $5 \mathrm{~h}$ or remdesivir alone. The mean $\mathrm{EC}_{50}$ values of $5 \mathrm{~h}$ and remdesivir determined with this set of the data were 4.0 and $9.0 \mu \mathrm{M}$, respectively. The figure was generated with GraphPad Prism 9. Bars indicate geometric mean $(n=2)$. b Representative images of fluorescent immunocytochemistry data from two independently conducted experiments are shown. SARS-CoV-2 antigens, F-actin, and nuclei are indicated in green, red, and blue, respectively. Source data are provided as a Source Data file.

when $20 \mu \mathrm{M}$ remdesivir and $20 \mu \mathrm{M}$ 5h were combined, producing the suppression by as much as $1,600,000$-fold $\left(1.4 \times 10^{4} ; 9.9 \times 10^{3}\right.$ $\left.2.1 \times 10^{4}\right)$ (Fig. 5a and Supplementary Table 2). The use of $40 \mu \mathrm{M}$ did not further the suppression, suggesting that $20 \mu \mathrm{M}$ combination of the two compounds exerted the maximal suppression of the viral replication. When examined using the Bliss additivism method that tests the presence or absence of synergism, additivism or antagonism ${ }^{30-32}$, the reduction achieved by combinations of the two agents was synergistic (Supplementary Table 2).

We also examined whether the synergistic effects of the combination were seen using immunocytochemistry. As seen in Fig. $5 \mathrm{~b}$, at $10 \mu \mathrm{M}$, both remdesivir alone and $5 \mathrm{~h}$ alone failed to completely block the infectivity of SARS-CoV-2 $\mathrm{WK}-521$ and a number of cells were infected and stained green. However, when these two compounds were combined, the cells were completely protected from viral infection (Fig. 5b), in line with the data shown in Fig. 5a. At $20 \mu \mathrm{M}$, in the presence of remdesivir or $5 \mathrm{~h}$, there was significant virus breakthrough; however, when combined, there was no breakthrough detected at all. The same was true when the two compounds were examined at $40 \mu \mathrm{M}$ (Supplementary Fig. 7 and Supplementary Table 2).

Molecular interactions of $5 \mathrm{~h}$ and GRL-1720 with SARS-CoV2's Mpro. To understand the molecular basis of the inhibition of SARS-CoV-2's Mpro by $5 \mathrm{~h}$, we determined the X-ray structure of

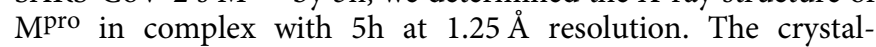
lographic asymmetric unit comprises a dimer form of Mpro. The dimer interface is highly conserved among the eight human coronaviruses $\mathrm{Mpro}_{\mathrm{s}}$ listed in Fig. 1a. Indeed, a number of previous studies reported that only the dimeric form of Mpro shows enzymatic activity (Fig. 1b-d) ${ }^{33,34}$. In fact, when we have gone over the amino acid sequences of Mpro of 102 different SARS-CoV-2 strains isolated in 12 nations and regions, whose full-length viral sequences were deposited to GenBank at National Center of Biotechnology Information (NCBI) by March 17,2020 , all strains proved to carry an identical Mpro amino acid sequence to the Mpro of NCBI Reference Sequence, NC_045512.2 


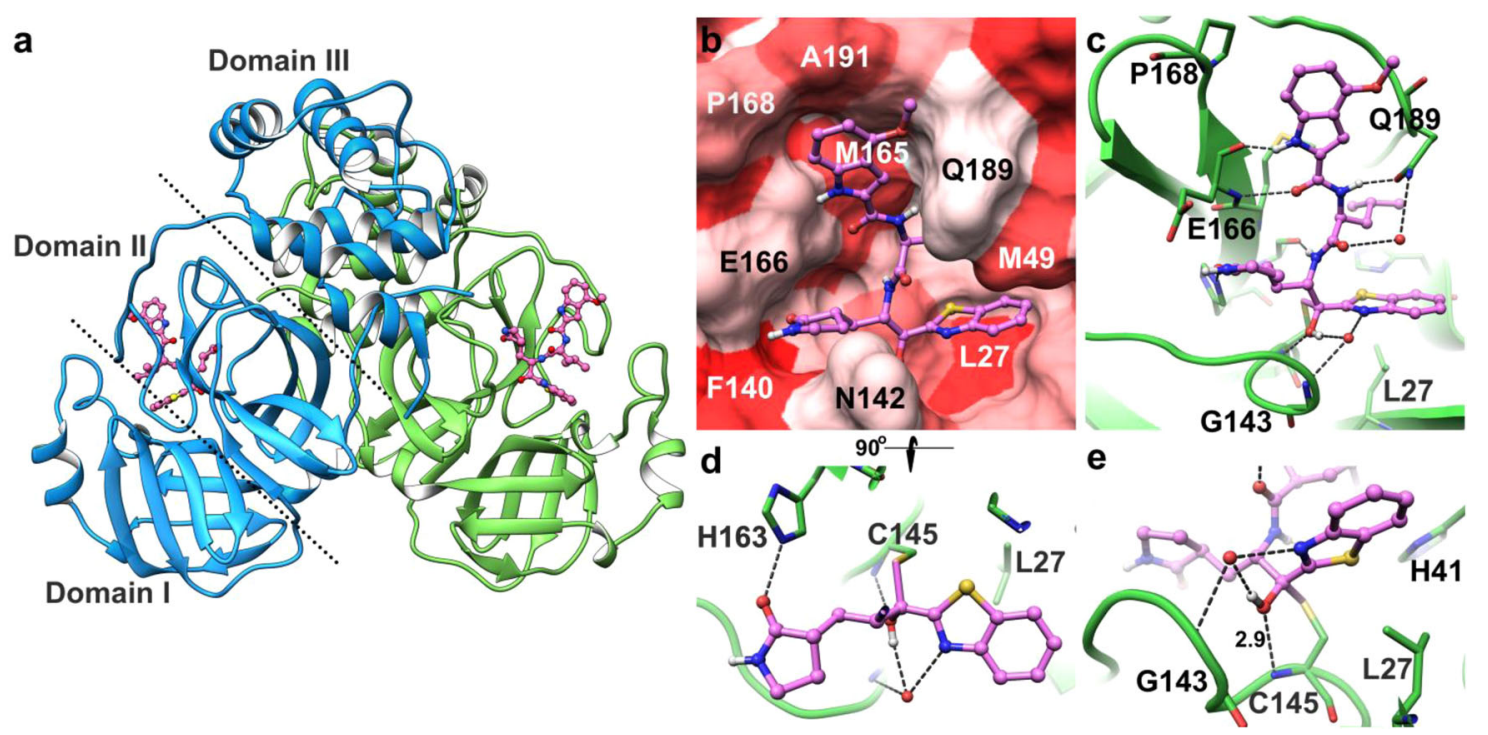

Fig. 6 The X-ray crystal structure of SARS-CoV-2 Mpro in complex with $\mathbf{5 h}$. a SARS-CoV-2 Mpro is shown in ribbon and $5 \mathrm{~h}$ in ball and stick

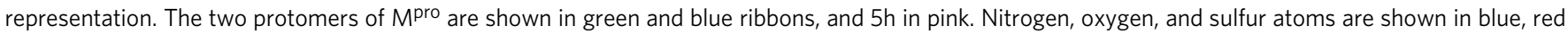
and yellow, respectively. Each protomer consists of three domains (only one protomer is labeled for clarity) and domains I and II mostly comprise of b-sheets and loops and forming the binding pocket. $\mathbf{b}$ Hydrophobicity of the binding pocket is represented by the intensities of red color, hydrophobic residues such as Leu-27 and Met-165 are shown in dark red, whereas polar or charged residues such as Glu-166, Gln-189 are shown in light red. While the distal edge of 4-methoxyindole-2-carbonyl group is surrounded by Pro-168 and Ala-191 on the top, the center part of the moiety faces to Met-165, which lies in the interior part of the binding groove. c Hydrogen bond interactions between $5 \mathrm{~h}$ (pink carbon atoms) and Mpro (green carbon atoms) are shown in black dashed lines. $5 \mathrm{~h}$ forms 8 direct hydrogen bonds with $\mathrm{M}^{\text {pro }}$ residues, additional polar interactions are mediated by water molecules (red spheres). d A $90^{\circ}$-rotated view of $5 \mathrm{~h}$ focuses on the interactions of 2-oxopyrrolidine and benzothiazole groups. While the nitrogen of 2 -oxopyrrolidine forms hydrogen bonds with the carboxylate oxygen of Glu-166 and carbonyl oxygen of Phe-140, the oxygen of 2-oxopyrrolidine forms a hydrogen bond with the imidazole group of His-163. The nitrogen of the P1' benzothiazole forms water-mediated hydrogen bonds with the backbone $\mathrm{NH}$ of $\mathrm{Gly}-143$ and carbonyl oxygen of Thr-26. e The hydroxyl group of $5 \mathrm{~h}$ is shown in the center, which forms a strong hydrogen bond with the backbone amide of Cys-145 ( $2.9 \AA$ ). Distances between atoms are shown in $\AA$.

(https://www.ncbi.nlm.nih.gov/nuccore/NC_045512) and the Mpro of SARS-CoV-2 (PDB:6LU7). In the X-ray crystallographic data collected, clear electron density of 5h (Supplementary Fig. 8) was observed inside the binding groove stretching between domain I and domain II (Fig. 6a). Detailed molecular interactions with Mpro are shown in the Fig. $6 \mathrm{~b}-\mathrm{e}$. $5 \mathrm{~h}$ fully occupies all binding pockets and is stabilized by six direct hydrogen bonds with the residues inside the binding groove of Mpro. Particularly, Glu-166 engages in the formation of two hydrogen bonds linking the main chain carbonyl and the amide group of Glu-166. In the central part of $5 \mathrm{~h}$, additional hydrogen bonds form with the sidechain oxygen of Gln-189 and the main chain carbonyl of His-164 (Fig. 6b, d). Since the majority of hydrogen bonds form through the main chain carbonyl and $\mathrm{NH}$ groups of Mpro, those interactions are less likely affected by potential mutations. In addition to hydrogen bonds, several hydrophobic residues contribute to binding affinity via van der Waals interactions (Fig. 6c). Inside the S2 sub-pocket, the distal benzene ring of the benzothiazole of $5 \mathrm{~h}$ is sandwiched by Leu-27 and Met-49. Overall, the chemical composition of $5 \mathrm{~h}$ matches well with the surface of the binding groove in terms of the hydrophobicity scale. The observed continuous electron density of the tetrahedral ketal and the sulfur atom of Cys-145 indicates the formation of a covalent bond between $5 \mathrm{~h}$ and Mpro (Fig. 6e, supplementary Fig. 8). The sulfur atom of Cys-145 undergoes nucleophilic addition reaction and forms a covalent bond with the carbonyl carbon $(-\mathrm{C}=\mathrm{O})$ next to the benzothiazole of $5 \mathrm{~h}$, resulting in the conversion of the carbonyl to an alcohol (-C-OH) and to the formation of one direct hydrogen bond and water-mediated hydrogen bond interactions around the three oxyanion hole residues, Cys-145 and Gly-143 (Fig. 6e). Unlike in most structures of the free and inhibited
SARS-CoV-2 Mpro (Supplementary Fig. 9), the "catalytic water", bound by His-41, His-164, Asp-187, and the main chain amide nitrogen of His-41, is not present in the structure of the $5 \mathrm{~h}$ complex. This significant modification of the active site is caused by the shift of the side chain of His-41 due to its interaction with the benzothiazole of the inhibitor, creating a direct hydrogen bond between the imidazole groups of His-41 and His-164.

GRL-1720 is an indoline chloropyridinyl ester. The mechanism of interaction of esters with SARS-CoV has been examined by others $^{35}$. We propose a similar mechanism for the interactions of GRL-1720 with SARS-CoV-2 Mpro, which is outlined in Supplementary Fig. 10. The catalytic His-41 and Cys-145 are involved in the nucleophilic attack on the ester carbon of GRL-1720. Following acylation, the chloropyridinyl group departs, and the carbonyl indoline moiety is bound to Cys-145 of Mpro through a covalent bond (indicated by a yellow arrow in Supplementary Fig. 11). The presence of a covalently-bound carbonyl indoline moiety was verified by electrospray ionization quadrupole time-of-flight mass spectrometry (ESI-QTOF/MS)(vide infra). The predicted structural interactions of the carbonyl indoline moiety of GRL-1720 with Mpro are shown in Supplementary Fig. 11. The carbonyl carbon is involved in hydrogen-bond interactions with the backbone amine nitrogens of Gly-143 and Cys-145 (Supplementary Fig. 11). Overall, $5 \mathrm{~h}$ has multiple additional favorable interactions with Mpro compared with that of GRL-1720, which may partially explain the much greater enzymatic inhibition and antiviral activity of $5 \mathrm{~h}$ compared to GRL-1720.

Analyses of interactions of GRL-1720 and $5 \mathrm{~h}$ using nanoLCESI-QTOF-MS. In order to ask whether GRL-1720 and 5h form 


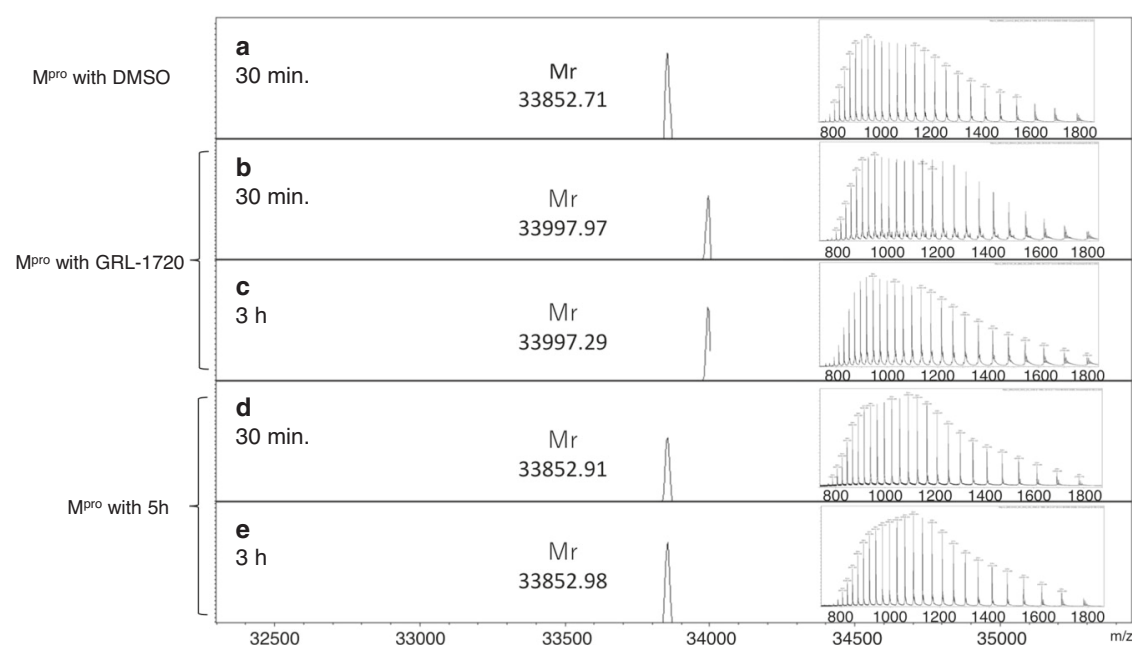

Fig. 7 Mass spectrometry analysis of apoMpro, GRL-1720- and 5h-treated Mpro. Deconvoluted mass spectra of $10 \mu \mathrm{M}$ apoMpro treated with DMSO (a), GRL-1720 (b and $\mathbf{c}$ ) and $5 \mathrm{~h}$ ( $\mathbf{d}$ and $\mathbf{e}$ ) are shown for $30 \mathrm{~min}$ and $3 \mathrm{~h}$, respectively. The insets show the molecular ion profiles for apoMpro, and GRL-1720and 5 h-treated Mpro. The theoretical molecular mass is 33,853.41 Da (average mass) for apoMpro and 33,998.56 Da (average mass) for the $1 \mathrm{H}$-indpline-4carbonyl group-binding form of $\mathrm{M}^{\text {pro. }}$.

covalent bonds, nanoLC-ESI-QTOF-MS experiments were performed to interrogate the nature of the interactions after treatment of Mpro with GRL-1720 or $5 \mathrm{~h}$ for $30 \mathrm{~min}$ and $3 \mathrm{~h}$. As compared with the mass of apoMpro (Fig. 7a for 30 min treatment), the mass increments of $+145.26 \mathrm{Da}$ (Fig. $7 \mathrm{~b}$ for $30 \mathrm{~min}$ treatment) and $+144.58 \mathrm{Da}$ (Fig. $7 \mathrm{c}$ for $3 \mathrm{~h}$ treatment) in the presence of GRL-1720, were observed. The increased size corresponds to the molecular weight of the bound $1 \mathrm{H}$-indoline-4carbonyl group. In the active site of $\mathrm{M}^{\mathrm{pro}}$, Cys-145 and His-41 appear to form a catalytic dyad (Supplementary Fig 10). Consequently, the sulfur atom gains nucleophilicity, and presumably exerts a nucleophilic attack on the electrophilic carbon atom of the polar carbonyl group from GRL-1720. In contrast, no changes in the mass were identified in Mpro treated with $5 \mathrm{~h}$ for $30 \mathrm{~min}$ or $3 \mathrm{~h}$ as compared with $\mathrm{M}^{\text {pro }}$ unexposed to $5 \mathrm{~h}$ (Fig. $7 \mathrm{~d}$, e). These data suggest that $5 \mathrm{~h}$ does form a covalent bond with Mpro as observed in the X-ray crystallographic analyses (Fig. 6); however, the covalent bonding is of a reversible nature as previously described by Vershueren et al. ${ }^{35}$.

Thermal stability of MPro in the absence or presence of GRL1720 and $5 \mathrm{~h}$. We also examined the thermal stability of Mpro in the presence of GRL-1720 and 5h using differential scanning fluorimetry (DSF). As illustrated in Fig. 8 , the $T_{m}$ value of Mpro alone in Experiment 1 was $53.63^{\circ} \mathrm{C}$, while in the presence of 5, 50, and $100 \mu \mathrm{M}$ of GRL-1720, the values decreased to 51.03, 49.39, and $47.95^{\circ} \mathrm{C}$, respectively (Fig. 8a). The observed shifts of $\mathrm{T}_{m}$ values to lower temperatures have reportedly been associated with an apparent destabilization of the protein by covalently-bound compounds ${ }^{36-38}$. Thus, these data corroborate that GRL-1720 forms a covalent bond with $M^{\text {pro }}$. By contrast, the $T_{m}$ value of $M^{\text {pro }}$ alone in Experiment 2 was $51.17^{\circ} \mathrm{C}$, while in the presence of 50 and $100 \mu \mathrm{M}$ of $5 \mathrm{~h}$, the values increased to 53.50 and $55.01{ }^{\circ} \mathrm{C}$ (Fig. 8b). Interestingly, in the presence of 5,50 , and $100 \mu \mathrm{M}$ of lopinavir, the $\mathrm{T}_{\mathrm{m}}$ values of $\mathrm{M}^{\text {pro }}$ turned out to be substantially lower at 49.31, $48.64^{\circ} \mathrm{C}$ and $48.87^{\circ} \mathrm{C}$ (Fig. 8c), suggesting that lopinavir does not stabilize Mpro but rather destabilizes the protein. Of note, the interpretation of a decreased $\mathrm{T}_{\mathrm{m}}$ in the case of lopinavir is complex. In general, destabilizers have been largely dismissed and removed from detailed investigations; however, all such destabilizers have been summarily placed into the non-specific binder category ${ }^{36-38}$. In conclusion, these thermal stability data suggest that GRL-1720 forms covalent interactions with $\mathrm{M}^{\text {pro, }}$, while $5 \mathrm{~h}$ likely forms reversible covalent interactions ${ }^{35}$ with Mpro. Based on the X-ray crystallographic analyses and thermal stability data, it should be reasonable to conclude that $5 \mathrm{~h}$ strongly interacts with $\mathrm{M}^{\mathrm{pro}}$ and potently inhibits its enzymatic activity as compared to GRL-1720.

\section{Discussion}

In the present study, we synthesized a panel of compounds based on previously known structures and their inhibitory activity against SARS-CoV and demonstrated that two small molecule compounds, GRL- $1720^{16}$ and compound $5 \mathrm{~h}^{20}$. Both compounds target the main protease (Mpro) of SARS-CoV-2 and potently block the infectivity, replication, and cytopathicity of SARS-CoV-2 ${ }^{\text {WK-521 }}$ as assessed using cell-based assays with RNA-qPCR, cytopathicity assays, and immunocytochemistry (Figs. 2 and 3). At a concentration of $20 \mu \mathrm{M}$, $5 \mathrm{~h}$ completely blocked the infection by SARS-CoV-2, while remdesivir, currently the only FDA-approved emergency therapeutic for treating patients with COVID-1939, permitted viral breakthrough at the same concentration. However, when $20 \mu \mathrm{M} 5 \mathrm{~h}$ was combined with $20 \mu \mathrm{M}$ remdesivir, that combination reduced the number of SARS-CoV-2 copies by the magnitude of $1.6 \times 10^{6}$ (Fig. 5), strongly suggesting that as in the case of antiretroviral therapy of HIV-1 infection, in which the use of one or two reverse transcriptase inhibitors and an HIV-1 protease or integrase inhibitor resulted in highly favorable antiretroviral effects ${ }^{40}$, such a combination might give much more favorable efficacy than remdesivir alone or $5 \mathrm{~h}$ alone. Of particular note, in the current study, we were able to sever the reduction of numbers of virus copy numbers due to the cytostatic/cytotoxic effects from virus-specific inhibitory activity of the test compounds. Our detailed immunocytochemistry experiments clearly segregated the virus-specific antiviral activity from the cytostatic/cytotoxic effects of the test compounds. We therefore conclude that no detectable anti-SARSCoV-2 activity is present in compounds such as HIV-1 protease inhibitors (nelfinavir and atazanavir) ${ }^{25-27}$ and shikonin ${ }^{24}$ that have previously been reportedly to be active against SARS-CoV-2. Thus far, over 80 SARS-CoV-2 Mpro structures in the PDB and some of them have the authentic sequence of the $\mathrm{N}$ terminus, and some do not. A detailed comparison of all these structures we conducted indicated that the nature of the $\mathrm{N}$ terminus and its disorder bear no 


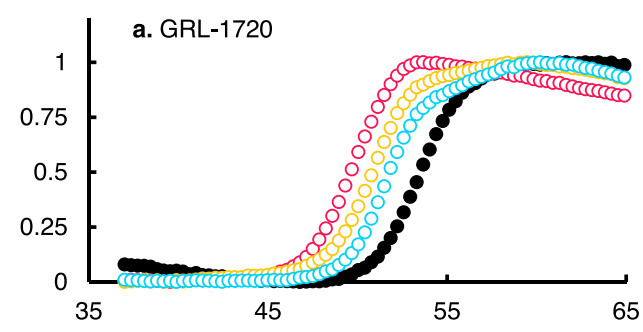

\begin{tabular}{lc}
\hline & $\mathrm{T}_{\mathrm{m}}\left({ }^{\circ} \mathrm{C}\right)$ \\
\hline Experiment 1 & \\
$\mathrm{M}^{\text {pro }}$ only & 53.63 \\
$\mathrm{M}^{\text {pro }}+100 \mu \mathrm{M}$ GRL-1720 (1:20) & 47.95 \\
$\mathrm{M}^{\text {pro }}+50 \mu \mathrm{M}$ GRL-1720 (1:10) & 49.39 \\
$\mathrm{M}^{\text {pro }}+5 \mu \mathrm{M}$ GRL-1720 (1:1) & 51.03
\end{tabular}

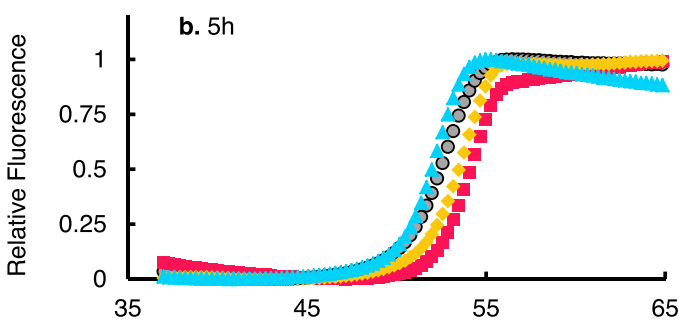

Experiment 2
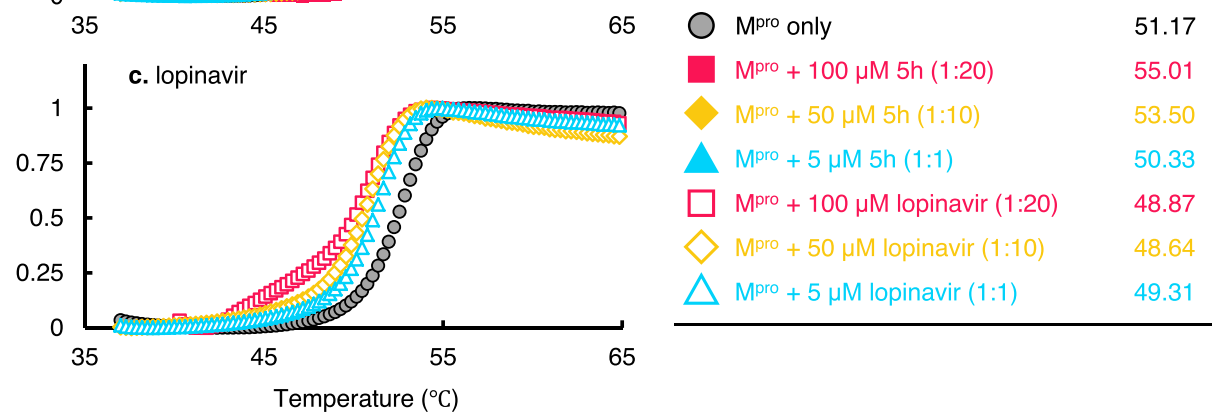

Fig. 8 Thermal stability of $\mathbf{M}^{\text {pro }}$ in the presence or absence of $\mathbf{5 h}$. Thermal stability of Mpro in the presence of GRL-1720 (a), 5h (b), and lopinavir (c) using differential scanning fluorimetry (DSF) was determined. Note in Experiment 1 that the $T_{m}$ value of $M^{p r o}$ alone was $53.63^{\circ} \mathrm{C}$, while in the presence of 50 and $100 \mu \mathrm{M}$ of GRL-1720, the values decreased to 49.39 and $47.95^{\circ} \mathrm{C}$, respectively, suggesting that the thermal stability of Mpro decreased when GRL1720 bound to $M$ pro, suggesting that GRL-1720 formed covalent bond with $M^{\mathrm{p} r o}$. In experiment 2 , the $\mathrm{T}_{\mathrm{m}}$ value of $\mathrm{M}^{\text {pro }}$ alone was $51.17{ }^{\circ} \mathrm{C}$, while in the presence of 50 and $100 \mu \mathrm{M}$ of $5 \mathrm{~h}$, the values increased to 53.50 and $55.01^{\circ} \mathrm{C}$, respectively, suggesting that the thermal stability of $\mathrm{M}$ pro increased when $5 \mathrm{~h}$ bound to Mpro. When Mpro was treated with 50 and $100 \mu \mathrm{M}$ lopinavir, decrement was seen with the $T_{m}$ values with 48.64 and 48.87 , suggesting that lopinavir non-specifically bound to Mpro (see the Results section). These data with the x-ray crystallographic analyses $5 \mathrm{~h}$ strongly interacts with $\mathrm{M}^{\mathrm{pro}}$ and potently inhibits its enzymatic activity as compared to GRL-1720. All the figures were generated with Microsoft Excel.

relationship to the mode of binding of the inhibitors. An additional structure of the $5 \mathrm{~h}$ inhibitor complex in a different crystal form was determined at a lower resolution, but using a construct with an authentic $\mathrm{N}$ terminus (PDB ID 6XR3). The structure discussed in the present study (PDB ID 7JKV) and the structure in 6XR3 nicely superimpose with an RMS $0.68 \AA$, and the substrate binding area is virtually the same. We also conclude that GRL-1720 and $5 \mathrm{~h}$ completely block the infectivity and cytopathicity of SARS-CoV-2 by specifically targeting Mpro of SARS-CoV-2.

Our structural analyses suggest that both GRL-1720 and 5h form interactions with several active site residues, including Cys145 of Mpro. The catalytic dyad, His-41 and Cys-145, is involved in the nucleophilic attack on the ester carbon of GRL-1720, and the carbonyl indoline moiety is bound to Cys-145 of Mpro through a covalent bond (Supplementary Fig. 11). Indeed, the presence of a covalently-bound carbonyl indoline moiety was verified with nanoLC-ESI-QTOF-MS (Fig. 7). Notably, X-ray structural analysis revealed that the sulfur in Cys-145 of Mpro undergoes a nucleophilic addition reaction by forming a covalent bond with $5 \mathrm{~h}$ (Fig. 6). However, it is also likely that 5h-Mpro covalently-linked ketal converts to a carbonyl group with noncovalent binding with Mpro in a reversible manner ${ }^{35}$. In fact, in our nanoLC-ESI-QTOF-MS studies, Mpro and $5 \mathrm{~h}$ eluted separately, indicating that they do not form a covalent bond under the conditions used for our nanoLC-ESI-QTOF-MS studies. Overall, both the covalently bound tetrahedral ketal as well as the noncovalent bound carbonyl form of $5 \mathrm{~h}$ likely make a number of interactions with the active site residues of $\mathrm{M}^{\text {pro }}$. 5h makes multiple additional favorable interactions with Mpro compared with GRL-1720, which may explain its much greater antiviral activity. Further, the thermal stability of Mpro significantly increased in the presence of $5 \mathrm{~h}$, corroborating that $5 \mathrm{~h}$ also forms non-covalent bond with Mpro (Fig. 8).

Of note, the report by Jin et al. ${ }^{24}$ showed that (i) shikonin fits well to the hydrophobic cavity of the catalytic active site of Mpro in their docking simulation attempt and (ii) it moderately inhibited the enzymatic activity of Mpro in their enzyme assay. In our cell-based assays, however, shikonin showed no detectable antiviral activity against SARS-CoV-2 (Fig. 4). Most recently, a paper on the structure of Mpro complexed with shikonin was published by $\mathrm{Li}$ et al. ${ }^{41}$, showing that shikonin forms a noncovalent bond with Mpro, although they did not report its actual antiviral activity against SARS-CoV-2. It is unknown as to whether further modification of shikonin can lead to the development of therapeutically useful compounds.

In conclusion, $5 \mathrm{~h}$, which shows potent antiviral activity and no significant detectable cytotoxicity, represents a promising lead compound to develop anti-SARS-CoV-2 agents. Moreover, the combination therapy using different class of agents, such as an Mpro inhibitor and an RdRp inhibitor, might be a promising therapeutic modality for treatment of SARS-CoV-2 infection.

\section{Methods}

Cells, viruses, and antiviral compounds. VeroE6 cells were obtained from Japanese Collection of Research Bioresources (JCRB) Cell Bank (Osaka, Japan) and were maintained in D-MEM supplemented with $10 \% \mathrm{FCS}, 100 \mu \mathrm{g} / \mathrm{ml}$ of penicillin, 
and $50 \mu \mathrm{g} / \mathrm{ml}$ of kanamycin. Human peripheral blood mononuclear cells (PBMCs) and HBTEC were purchased from Lonza (Basel, Switzerland) and Lifeline Cell Technology (Frederick, MD), respectively. Calu-3 was kindly provided by Dr. Kawaoka (The University of Tokyo, Tokyo, Japan) SARS-CoV-2 JPN/TY/WK 521 strain (SARS-CoV-2 WK-521) was obtained from National Institute of Infectious Diseases (Tokyo, Japan). Antiviral agents, GRL-1720 and compound $5 h^{20}$ were synthesized and characterized (Supplementary Figs. 1 and 2) by Dr. Ghosh who is listed in co-author in this study, and shikonin was kindly provided by Dr. Hata (Kumamoto University, Kumamoto, Japan). Nelfinavir, atazanavir (Sigma-Aldrich, St. Louis, MO), and remdesivir (Selleck, Houston, TX) were purchased. All compounds were dissolved in DMSO at $20 \mathrm{mM}$ concentrations as stock solutions.

\section{SARS-CoV-2 Mpro inhibition assays. SARS-CoV-2 Mpro/3CLpro}

(Accession \#: MN908947) with the authentic N- and C-terminal residues that are released after cleavage from the polyprotein was used for all kinetic studies. The details for expression and purification of this fully active SARS-CoV-2 Mpro construct has recently been described ${ }^{42}$. In general, inhibition of SARS-CoV-2 Mpro by GRL1720 and $5 \mathrm{~h}$ was assessed using a continuous, fluorescence assay and the FRET-based substrate UIVT3 (HiLyte Fluor ${ }_{488}{ }^{\text {TM }}$-ESATLQSGLRKAK-QXL ${ }_{520}{ }^{\mathrm{TM}_{-}} \mathrm{NH}_{2}$ ) (Anaspec, Fremont, CA). The assay buffer consisted of $50 \mathrm{mM}$ HEPES pH 7.50, $0.1 \mathrm{mg} / \mathrm{mL}$ BSA, $0.01 \%$ Triton X-100, 2 mM DTT, 1\% DMSO and a final enzyme concentration of $200 \mathrm{nM}$. Kinetic assays were performed in Costar 3694 EIA/RIA 96-well half-area, flat bottom, black polystyrene plates (Corning, Corning, NY) at $25^{\circ} \mathrm{C}$. The increase in fluorescence intensity of SARS-CoV-2 $\mathrm{M}^{\text {pro }}$ catalyzed reactions was measured at an emission wavelength of $528 \mathrm{~nm}(20 \mathrm{~nm}$ bandwidth) using an excitation wavelength of 485 (bandwidth $20 \mathrm{~nm}$ ) using either a CLARIOstar Plate Reader (BMG Labtech, Cary, NC) or a Synergy H1 hybrid multi-mode plate reader (BioTek, Winooski, VT). The initial rates of the reactions were then determined from the slopes of the Relative Fluorescence Units (RFU) produced during the initial rate period of the enzyme by time in minutes, yielding RFU $\mathrm{min}^{-1}$. Experimental details for the treatment of GRL1720 kinetic data for irreversible covalent inhibition and $5 \mathrm{~h}$ kinetic data for reversible covalent inhibition are provided in Supplementary information.

Antiviral activity and cytotoxicity assay. For antiviral assay, cells were exposed to virus at multiplicity of infection (MOI) of 0.05 for $1 \mathrm{~h}$, virus was then washed out, and cells were cultured in the presence or absence of compounds. After 3 days, cell culture supernatants were harvested and viral RNA was extracted using QIAamp Viral RNA Mini Kit (QIAGEN, Hilden, Germany), and quantitative RT-PCR (RT-qPCR) was then performed using One Step PrimeScript III RT-qPCR Mix (Takara Bio, Shiga, Japan) following manufactures' instructions. The primers and probe used for detecting SARS-CoV-2 envelope ${ }^{43}$ were: $5^{\prime}$-ACT TCT TTT TCT TGC TTT CGT GGT-3' (forward), 5'-GCA GCA GTA CGC ACA CAA TC- $3^{\prime}$ (reverse), and 5'-FAMCTA GTT ACA CTA GCC ATC CTT ACT GC-BHQ1-3' (probe). Each assay was conducted in duplicate.

To determine cytotoxicity of a compound, VeroE6 and Calu-3 cells, and human primary cells, PHA-PBMC and HBTEC, were plated in a 96-well plate at a density of $10^{4}$ cells in $200 \mu \mathrm{L}$ culture medium (final) in each well and were continuously exposed to various concentrations of the compound for 3 days. The cytotoxicity of compounds was determined using Cell Counting Kit-8 (Dojindo, Kumamoto, Japan). Each assay was conducted in duplicate.

In the experiments using airway epithelial cells, we used ALI culture model (EpiAirway; MatTeck, Ashland, MA). The maintenance medium with supplement (MatTeck) containing test compounds was added to ALI cultures $(100 \mu \mathrm{L}$ to the apical chamber and $500 \mu \mathrm{L}$ to the basement chamber) and $100 \mu \mathrm{L}$ of SARS-CoV-2 ${ }^{\mathrm{WK}-521}$ viral inoculum $\left(2 \times 10^{4} \mathrm{TCID}_{50}\right.$ per well $)$ was added to the apical chamber. After $3 \mathrm{~h}$ of viral exposure, cells were washed and $500 \mu \mathrm{L}$ of fresh maintenance medium containing the same concentration of the test compound was added to the basement chamber and the cells were cultured for 3 days. Immunocytochemistry and RNAqPCR were performed after 3 days post viral exposure.

Immunocytochemistry. Cells in 96-well microtiter culture plate were fixed with 4\% paraformaldehyde in PBS for 15 min, washed with PBS $(300 \mu \mathrm{L} /$ well $)$ three times for $5 \mathrm{~min}$ each, and were then blocked with a blocking buffer (10\% goat serum, $1 \%$ BSA, $0.3 \%$ Triton X-100, and PBS $1 \mathrm{X}$ ) for $1 \mathrm{~h}$. After removing the blocking buffer, the cells were immediately stained with primary antibodies: convalescent IgG fraction (1/500 dilution), which was isolated from serum of a convalescent COVID-19 individual using spin column-based antibody purification kit (Cosmo Bio, Tokyo, Japan), overnight at $4{ }^{\circ} \mathrm{C}$. The stained cells were washed with PBS $(300 \mu \mathrm{L} /$ well) three times for $5 \mathrm{~min}$ each, and the cells were incubated with the secondary antibody: goat polyclonal anti-human-IgG-Alexa Fluor 488 Fab fragment antibody (1/200 dilution)(Jackson ImmunoResearch Laboratories, Inc, West Grove, PA, USA), together with Texas Red' $-\mathrm{X}$ dye conjugated Phalloidin (Thermo Fisher Scientific, Waltham, MA, USA) for F-actin visualization for $2 \mathrm{~h}$. After washing the cells with PBS ( $300 \mu \mathrm{L} /$ well) three times for $5 \mathrm{~min}$ each, DAPI solution (Thermo Fisher Scientific) in PBS $(50 \mu \mathrm{L} /$ well) was added to stain nuclei. Signals were acquired with a Cytation 5 Cell Imaging Multi-Mode Reader and Gen 5 (v3.05) software.(BioTek).
Analysis for combination effects. The Bliss additivism model ${ }^{30-32}$ was used to classify the effect of combining two agents as additive, synergistic, or antagonistic A theoretical curve was calculated for combined inhibition using the equation bliss index $\left(\mathrm{E}_{\mathrm{bliss}}\right)=\mathrm{E}_{\mathrm{A}}+\mathrm{E}_{\mathrm{B}}-\mathrm{E}_{\mathrm{A}} \times \mathrm{E}_{\mathrm{B}}$, where $\mathrm{E}_{\mathrm{A}}$ and $\mathrm{E}_{\mathrm{B}}$ are the fractional inhibitions obtained by drug $\mathrm{A}$ alone and drug $\mathrm{B}$ alone at specific concentrations. $\mathrm{E}_{\mathrm{A}+\mathrm{B}}$ is the fractional inhibition obtained by the combination with drug $A$ and $B$. Here, $E_{b l i s s}$ is the fractional inhibition that would be expected if the combination effect of the two drugs was exactly additive. If the experimentally measured fractional inhibition $\left(\mathrm{E}_{\mathrm{A}+\mathrm{B}}\right)$ is less than $\mathrm{E}_{\mathrm{bliss}}$, the combination effect is judged to be synergistic. If the experimentally measured fractional inhibition is greater than $\mathrm{E}_{\mathrm{bliss}}$, the combination effect is judged to be antagonistic.

Molecular modeling of the interaction of GRL-1720 with $\mathbf{M}^{\text {pro }}$. A crystal structure of SARS-CoV-2 main protease (MPro)(RCSB PDB ID 6Y2F) was used for molecular docking of GRL-1720. The crystal structure was processed for molecular docking by deleting the water molecules and dimethyl sulfoxide. Hydrogen atoms were added, and appropriate bond orders were assigned to the protein atoms, and the bound inhibitor. The protonation states of the asparagines, glutamines, and histidines were determined. Using the OPLS3 force field (used for all geometry minimizations), a restrained minimization was performed (with a cut-off of $0.30 \AA$ for root mean square difference of heavy atoms from the crystal structure coordinates). The above were performed with the Protein Preparation wizard present in Maestro. The structure thus obtained was used for molecular docking. The inhibitor molecule GRL-1720 was built in Maestro, and minimized conformations were generated using the LigPrep module. The covalent docking sub-module of Glide was used and a docking grid encompassing the volume occupied by the bound inhibitor from the crystal structure was generated. A nucleophilic attack by Cys145 of SARS-CoV2 protease on GRL-1720 was chosen as the mode of reaction while determining the docked interaction poses. This was because the literature on SARS-CoV and SARS-CoV-2 demonstrates that the active site cysteine undergoes nucleophilic addition reactions with formation of a covalent bond with appropriate functional groups such as a carbonyl carbon. Recent crystal structures also demonstrate that Cys-145 of SARS-CoV-2 protease forms covalent bond with inhibitors ${ }^{24}$. Subsequent to the formation of the covalent bond with MPro, GRL1720 , an ester, undergoes cleavage of the chloropyridinyl group forming a thiocarbonyl complex. The interactions of the thiocarbonyl complex with $\mathrm{M}^{\text {pro }}$ were determined by full geometry optimization. All simulations were done using software versions/modules as present in Maestro Version 10.7.015 (Schrödinger LLC, New York, NY).

Expression and preparation of $\mathbf{M}^{\mathbf{p r o}}$. The SARS-CoV2 $\mathrm{M}^{\mathrm{pro}}$-encoding sequence was cloned into pGEX-4T1 vector (Genscript, Piscataway, NJ). Prepared expression vector with GST tag was transformed to BL21-CodonPlus(DE3)-RIL strain (Agilent, Santa Clara, CA) by heat-shock transformation. The culture was grown in a shake flask containing $20 \mathrm{~mL}$ of LB medium plus ampicillin and chloramphenicol $\left(\mathrm{LB}^{\mathrm{Am}+} / \mathrm{Cp}+\right)$ at $37^{\circ} \mathrm{C}$ overnight. Twenty milliliter of the grown culture was added to $1 \mathrm{~L}$ of $\mathrm{LB}^{\mathrm{Am}+} / \mathrm{Cp}+$. The $\mathrm{LB}^{\mathrm{Am}+} / \mathrm{Cp}+$ culture was grown in flasks to an optical density of 0.5 at $600 \mathrm{~nm}$ at $37^{\circ} \mathrm{C}$, and the expression was induced by addition of $0.5 \mathrm{mM}$ isopropyl $\beta$-D-thiogalactopyranoside for $6 \mathrm{~h}$ at $25^{\circ} \mathrm{C}$. After examination, the culture was spun down for pellet collection, and thus obtained pellets were stored at $-80^{\circ} \mathrm{C}$ until use. For purification of GST-linked Mpro, each pellet was resuspended in PBS and lysed by sonication. The cell lysates were separated into a supernatant fraction and inclusion body fraction by centrifugation. The GSTtagged $\mathrm{M}^{\text {pro }}$ was confirmed to be present in the supernatant fraction. The GSTtagged Mpro was bound to $5 \mathrm{~mL}$ of Glutathione-Superflow Resin (Takara Bio). The resin was washed five times using $20 \mathrm{~mL}$ PBS. To cleave the GST tag form Mpro forty milliliter of PBS including $100 \mathrm{U}$ of thrombin (GE Healthcare, Chicago, IL) was added to the resin and was incubated for $16 \mathrm{~h}$ at $25^{\circ} \mathrm{C}$. Following thrombin cleavage, intact $\mathrm{Mpro}^{\mathrm{pro}}$ with an additional $\mathrm{N}$-terminal glycine residue was released from GST. Additional residue, Glysine does not influence to the structure/conformation of SARS-CoV-2 Mpro. After incubation, GST-tag-cleaved Mpro was transferred to the supernatant form the resin. the GST-tag-cleaved Mpro was collected and diluted three times using buffer A (10 mM Tris pH7.5, $1 \mathrm{mM}$ EDTA). The diluted $\mathrm{M}^{\mathrm{pro}}$ was further purified by using HiTrap Q (GE Healthcare). The purified and concentrated SARS-CoV-2 $\mathrm{M}^{\text {pro }}(10-13 \mathrm{mg} / \mathrm{mL})$ was stored in buffer A.

Crystallization of $\mathbf{M}^{\text {pro }}$ and compound $\mathbf{5 h}$. The $\mathrm{M}^{\mathrm{pro}}$ was concentrated up to $3 \mathrm{mg} / \mathrm{mL}$ and incubated with $300 \mu \mathrm{M} 5 \mathrm{~h}$ for $1 \mathrm{~h}$ before crystallization. Crystals were grown using hanging drop vapour diffusion method at $20^{\circ} \mathrm{C}$. The reservoir solution contained 0.1 M MES pH 5.8, 15\% polyethylene glycol (PEG) 6000, and 3\% DMSO. Crystals were soaked briefly in a cryoprotection solution containing $0.1 \mathrm{M}$ MES pH 6.0, 35\% PEG 400 5\% DMSO. X-ray data were collected at SPring-8 BL41XU (Hyōgo, Japan) and processed using DIALS using xia2 incorporated in ccp $42_{2}{ }^{44}$. The source wavelength for the data collection was $1.0 \AA$ A. Data collection statistics are shown in Supplementary Table S3. The phase problem was solved by molecular replacement using MolRep ${ }^{45}$ using the $2.16 \AA$ structure of Mpro (PDB ID:6LU7) as a model. All water molecules and ligand atoms were omitted from the starting model. Subsequent cycles of refinement to $1.25 \AA$ resolution were 
performed in REFMAC5 ${ }^{46}$. Structure file of $5 \mathrm{~h}$ was generated using the Dundee PRODRG2 server ${ }^{47}$ and manually fitted to the electron density. All structural figures were produced with PyMOL and UCSF Chimera ${ }^{48}$. The data were deposited into the PDB under ID: 7JKV.

Electrospray ionization quadrupole time-of-flight mass spectrometry (ESIQTOF/MS) analysis. To detect the molecular weight of the $\mathrm{M}^{\mathrm{Pro}}$, analysis was done using a quadrupole-time-of-flight (QTOF) mass spectrometer equipped with a Captive Spray electrospray ionization platform in the positive mode (impact II, Bruker Daltonics Bremen, Germany) with liquid chromatography (Ultimate 3000 HPLC, Thermo Fisher scientific). A sample $(1 \mu \mathrm{l}, 1 \mathrm{pmol})$ was separated on an Acclaim PepMap 100 C18LC column $(0.075 \mathrm{~mm} \times 150 \mathrm{~mm}, 2 \mu \mathrm{m}$ particle $)$ (Thermo Fisher scientific) over $35 \mathrm{~min}$ using a $2 \%$ acetonitrile gradient. Separations started with $95 \%$ buffer A, and $5 \%$ buffer B (acetonitrile with $0.1 \%$ formic acid) to $70 \%$ buffer B and then ramped to $95 \%$ in the following $5 \mathrm{~min}$ and then returned to starting conditions 5 min later. The intact and modified forms of $M^{\text {pro eluted at }}$ $\sim 27 \mathrm{~min}$. Following ion source parameters have been applied: dry Heater: $150^{\circ} \mathrm{C}$, dry Gas: $8.0 \mathrm{~L} / \mathrm{min}$, capillary voltage: $1000 \mathrm{~V}$, End plate offset: $-500 \mathrm{~V}$. MS scans have been acquired at a spectra rate of $1 \mathrm{~Hz}$ at a mass range from 100 to $3000 \mathrm{~m} / \mathrm{z}$. Molecular weights by protein deconvolution were determined using DataAnalysis 4.4 (Bruker Daltonics, Bremen, Germany).

\section{Thermal stability of $\mathbf{M}^{\text {pro }}$ in the absence or presence of $5 \mathrm{~h}$ or lopinavir} Thermal stability was examined using the DSF. Mpro preparation $(50 \mu \mathrm{M}$ dissolved in $10 \mathrm{mM}$ Tris (pH 7.5) and $1 \mathrm{mM}$ EDTA was mixed with various amounts of a test compound and incubated at $37^{\circ} \mathrm{C}$ for $3 \mathrm{~h}$. Subsequently, $30 \mu \mathrm{L}$ of the solution was successively heated from $15{ }^{\circ} \mathrm{C}$ to $95^{\circ} \mathrm{C}$, and the changes of fluorescence intensity were documented using the real-time PCR system (Applied Biosystems). The $\mathrm{Tm}$ (50\% melting temperature) values were determined as the temperature at which the relative fluorescent intensity became $50 \%$. Note that the thermal stability curves of $\mathrm{M}^{\text {pro }}$ with $5 \mathrm{~h}$ at the molar ratios of 1:10 and 1:20 shifted to the higher temperature (to the right). The thermal stability curves of Mpro did not shift with lopinavir as compared with that with no agent.

Reporting summary. Further information on research design is available in the Nature Research Reporting Summary linked to this article.

\section{Data availability}

Crystal structure data that support the findings of this study have been deposited in Protein Data Bank with the PDB ID: 6XR3, 7JKV. All relevant data supporting the findings in this study are available from the corresponding author upon reasonable request. Source data are provided with this paper.

Received: 26 May 2020; Accepted: 16 December 2020; Published online: 28 January 2021

\section{References}

1. Zhu, N. et al. A Novel Coronavirus from Patients with Pneumonia in China, 2019. N. Engl. J. Med. 382, 727-733 (2020).

2. Mitsuya, H. \& Kokudo, N. Sustaining containment of COVID-19: global sharing for pandemic response. Glob. Health Med. 2, 53-55 (2020).

3. Livingston, E. \& Bucher, K. Coronavirus Disease 2019 (COVID-19) in Italy. JAMA, https://doi.org/10.1001/jama.2020.4344 (2020).

4. Li, Q. et al. Early Transmission Dynamics in Wuhan, China, of Novel Coronavirus-Infected Pneumonia. N. Engl. J. Med. 382, 1199-1207 (2020).

5. World Health Organization. Coronavirus disease (COVID-19) Situation Report, https://www.who.int/emergencies/diseases/novel-coronavirus-2019

6. Coronaviridae Study Group of the International Committee on Taxonomy of Viruses. The species Severe acute respiratory syndrome-related coronavirus: classifying 2019-nCoV and naming it SARS-CoV-2. Nat. Microbiol. 5, 536-544 (2020).

7. Hilgenfeld, R. From SARS to MERS: crystallographic studies on coronaviral proteases enable antiviral drug design. FEBS J. 281, 4085-4096 (2014).

8. Muramatsu, T. et al. Autoprocessing mechanism of severe acute respiratory syndrome coronavirus $3 \mathrm{C}$-like protease (SARS-CoV 3CLpro) from its polyproteins. FEBS J. 280, 2002-2013 (2013).

9. Li, C. et al. Maturation mechanism of severe acute respiratory syndrome (SARS) coronavirus 3C-like proteinase. J. Biol. Chem. 285, 28134-28140 (2010).

10. Lindner, H. A. et al. The papain-like protease from the severe acute respiratory syndrome coronavirus is a deubiquitinating enzyme. J. Virol. 79, 15199-15208 (2005).

11. Barretto, N. et al. The papain-like protease of severe acute respiratory syndrome coronavirus has deubiquitinating activity. J. Virol. 79, 15189-15198 (2005).
12. Zhang, L. et al. Crystal structure of SARS-CoV-2 main protease provides a basis for design of improved alpha-ketoamide inhibitors. Science, https://doi. org/10.1126/science.abb3405 (2020).

13. Jacobs, J. et al. Discovery, synthesis, and structure-based optimization of a series of $\mathrm{N}$-(tert-butyl)-2-(N-arylamido)-2-(pyridin-3-yl) acetamides (ML188) as potent noncovalent small molecule inhibitors of the severe acute respiratory syndrome coronavirus (SARS-CoV) 3CL protease. J. Med. Chem. 56, 534-546 (2013).

14. Xue, X. et al. Structures of two coronavirus main proteases: implications for substrate binding and antiviral drug design. J. Virol. 82, 2515-2527 (2008).

15. Jain, R. P. et al. Synthesis and evaluation of keto-glutamine analogues as potent inhibitors of severe acute respiratory syndrome 3CLpro. J. Med. Chem. 47, 6113-6116 (2004).

16. Ghosh, A. K. et al. Design, synthesis and antiviral efficacy of a series of potent chloropyridyl ester-derived SARS-CoV 3CLpro inhibitors. Bioorg. Med. Chem. Lett. 18, 5684-5688 (2008).

17. Ghosh, A. K., Xi, K., Johnson, M. E., Baker, S. C. \& Mesecar, A. D. Progress in Anti-SARS Coronavirus Chemistry, Biology and Chemotherapy. Annu Rep. Med. Chem. 41, 183-196 (2007).

18. Ghosh, A. K. et al. Structure-based design, synthesis, and biological evaluation of peptidomimetic SARS-CoV 3CLpro inhibitors. Bioorg. Med. Chem. Lett. 17, 5876-5880 (2007)

19. Ghosh, A. K. et al. Design and synthesis of peptidomimetic severe acute respiratory syndrome chymotrypsin-like protease inhibitors. J. Med. Chem. 48, 6767-6771 (2005)

20. Thanigaimalai, P. et al. Development of potent dipeptide-type SARS-CoV 3CL protease inhibitors with novel P3 scaffolds: design, synthesis, biological evaluation, and docking studies. Eur. J. Med. Chem. 68, 372-384 (2013).

21. Ghosh, A. K., Brindisi, M., Shahabi, D., Chapman, M. E. \& Mesecar, A. D. Drug Development and Medicinal Chemistry Efforts toward SARSCoronavirus and Covid-19 Therapeutics. ChemMedChem, https://doi.org/ $10.1002 / \mathrm{cmdc} 202000223$ (2020)

22. Filion, L. G., Logan, D., Gaudreault, R. \& Izaguirre, C. A. Inhibition of HIV-1 replication by daunorubicin. Clin. Investig. Med. 16, 339-347 (1993)

23. Bergamini, A. et al. Selective inhibition of HIV replication by adriamycin in macrophages but not in lymphocytes. AIDS Res. Hum. Retroviruses 8 1239-1247 (1992)

24. Jin, Z. et al. Structure of $\mathrm{M}(\mathrm{pro})$ from SARS-CoV-2 and discovery of its inhibitors. Nature 582, 289-293 (2020).

25. Xu, Z. et al. Nelfinavir Is Active Against SARS-CoV-2 in Vero E6 Cells. ChemRxiv, https://doi.org/10.26434/chemrxiv.12039888.v1 (2020).

26. Norio Yamamoto, S. M., Tyuji Hoshino, Naoki Yamamoto. Nelfinavir inhibits replication of severe acute respiratory syndrome coronavirus 2 in vitro. bioRxiv, https://doi.org/10.1101/2020.04.06.026476 (2020).

27. Fintelman-Rodrigues N, S. C., et al. Atazanavir inhibits SARS-CoV-2 replication and pro-inflammatory cytokine production. bioRxiv, https://doi. org/10.1101/2020.04.04.020925 (2020).

28. Yin, W. et al. Structural basis for inhibition of the RNA-dependent RNA polymerase from SARS-CoV-2 by remdesivir. Science, https://doi.org/10.1126/ science.abc1560 (2020).

29. Gordon, C. J. et al. Remdesivir is a direct-acting antiviral that inhibits RNAdependent RNA polymerase from severe acute respiratory syndrome coronavirus 2 with high potency. J. Biol. Chem. 295, 6785-6797 (2020).

30. Buck, E. et al. Rapamycin synergizes with the epidermal growth factor receptor inhibitor erlotinib in non-small-cell lung, pancreatic, colon, and breast tumors. Mol. Cancer Ther. 5, 2676-2684 (2006).

31. Berenbaum, M. C. Criteria for analyzing interactions between biologically active agents. Adv. Cancer Res. 35, 269-335 (1981).

32. Bliss, C. I. The calculation of microbial assays. Bacteriol. Rev. 20, 243-258 (1956).

33. Shi, J. H., Sivaraman, J. \& Song, J. X. Mechanism for controlling the dimermonomer switch and coupling dimerization to catalysis of the severe acute respiratory syndrome coronavirus 3C-like protease. J. Virol. 82, 4620-4629 (2008).

34. Fan, K. Q. et al. Biosynthesis, purification, and substrate specificity of severe acute respiratory syndrome coronavirus 3C-like proteinase. J. Biol. Chem. 279, 1637-1642 (2004).

35. Verschueren, K. H. et al. A structural view of the inactivation of the SARS coronavirus main proteinase by benzotriazole esters. Chem. Biol. 15, 597-606 (2008).

36. Wossner, N. et al. Sirtuin 1 Inhibiting Thiocyanates (S1th)-A New Class of Isotype Selective Inhibitors of $\mathrm{NAD}(+)$ Dependent Lysine Deacetylases. Front. Oncol. 10, 657 (2020).

37. Simeonov, A. Recent developments in the use of differential scanning fluorometry in protein and small molecule discovery and characterization. Expert Opin. Drug Disco. 8, 1071-1082 (2013).

38. Weber, P. C. \& Salemme, F. R. Applications of calorimetric methods to drug discovery and the study of protein interactions. Curr. Opin. Struct. Biol. 13, 115-121 (2003). 
39. Beigel, J. H. et al. Remdesivir for the Treatment of Covid-19 - Preliminary Report. N. Engl. J. Med., https://doi.org/10.1056/NEJMoa2007764 (2020).

40. Bennett, K. K., DeGruttola, V. G., Marschner, I. C., Havlir, D. V. \& Richman, D. D. Baseline predictors of CD4 T-lymphocyte recovery with combination antiretroviral therapy. J. Acquir. Immune Defic. Syndr. 31, 20-26 (2002).

41. Li, J. et al. Crystal structure of SARS-CoV-2 main protease in complex with the natural product inhibitor shikonin illuminates a unique binding mode. Sci. Bull (Beijing), https://doi.org/10.1016/j.scib.2020.10.018 (2020).

42. Anson, B. et al. Broad-spectrum inhibition of coronavirus main and papainlike proteases by HCV drugs. Res. Square, https://doi.org/10.21203/rs.3.rs26344/v1 (2020).

43. Huang, C. et al. Clinical features of patients infected with 2019 novel coronavirus in Wuhan, China. Lancet 395, 497-506 (2020).

44. Winter, G. et al. DIALS: implementation and evaluation of a new integration package. Acta Crystallogr D. Struct. Biol. 74, 85-97 (2018).

45. Vagin, A. \& Teplyakov, A. Molecular replacement with MOLREP. Acta Crystallogr D. Biol. Crystallogr 66, 22-25 (2010).

46. Murshudov, G. N. et al. REFMAC5 for the refinement of macromolecular crystal structures. Acta Crystallogr D. Biol. Crystallogr 67, 355-367 (2011).

47. Schuttelkopf, A. W. \& van Aalten, D. M. PRODRG: a tool for high-throughput crystallography of protein-ligand complexes. Acta Crystallogr. D. Biol. Crystallogr. 60, 1355-1363 (2004).

48. Pettersen, E. F. et al. UCSF Chimera-a visualization system for exploratory research and analysis. J. Comput. Chem. 25, 1605-1612 (2004).

\section{Acknowledgements}

The authors thank Ms. Asuka Fujiwara, National Center for Global Health and Medicine (Tokyo, Japan), for technical help. The authors also thank Dr. Hiroyuki Hata, Kumamoto University (Kumamoto Japan), for helpful discussion. The present work was supported by a grant for Development of Novel Drugs for Treating COVID-19 from the Intramural Research Program of National Center for Global Health and Medicine (H.M., 19A3001 and S.H., 20A2001D), in part by Japan Agency for Medical Research and Development (AMED)(H.M., 20fk0108257), in part by the Intramural Research Program of the Center for Cancer Research, National Cancer Institute, National Institutes of Health (H.M. and A.W.), in part with Federal funds from the National Cancer Institute, NIH, under Contract No. HHSN261200800001E (to M.L.), and in part by the National Institute of Allergy and Infectious Diseases, National Institutes of Health (A.K.G., AI150466 and AI085089, and A.D.M., contract No. HHSN272201700060C). We also acknowledge the support of the Biomedical Research Core of the Tohoku University Graduate School of Medicine. The synchrotron radiation experiment was performed at BL41XU of SPring-8 with the approval of the Japan Synchrotron Radiation Research Institute (JASRI) (proposal no. 2020A1778). This study utilized the high-performance computational capabilities of the Biowulf Linux cluster at the National Institutes of Health, Bethesda, MD (https://hpc.nih.gov). The content of this publication is solely the responsibility of the authors and does not necessarily represent the official views or policies of the
Department of Health and Human Services, nor does the mention of trade names, commercial products, or organizations imply endorsement by the U. S. Government.

\section{Author contributions}

Conceptualization, S.H., D.A.D., R.Y., A.K.G., and H.M.; investigation, S.H., N.H.-K, H.H., S.R.A., J.R., H.B., D.D., B.J.A., E.K.L., Y.T., N.T., N.K., K.M., K.H., M.L., and S.M.; methodology, S.H., N.H.-K., H.B., D.D., B.J.A., A.D.M., A.W., A.K.G., and H.M.; original draft writing, S.H. and H.M.; writing-review and editing, all authors; Funding acquisition, S.H., M.L., A.W., A.D.M., A.K.G. and H.M.

\section{Competing interests}

The authors declare no competing interests.

\section{Additional information}

Supplementary information is available for this paper at https://doi.org/10.1038/s41467021-20900-6.

Correspondence and requests for materials should be addressed to H.M.

Peer review information Nature Communications thanks Andrey Kovalevsky, Antonio Rescifina, and the other, anonymous, reviewer(s) for their contribution to the peer review of this work.

Reprints and permission information is available at http://www.nature.com/reprints

Publisher's note Springer Nature remains neutral with regard to jurisdictional claims in published maps and institutional affiliations.

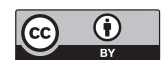

Open Access This article is licensed under a Creative Commons Attribution 4.0 International License, which permits use, sharing, adaptation, distribution and reproduction in any medium or format, as long as you give appropriate credit to the original author(s) and the source, provide a link to the Creative Commons license, and indicate if changes were made. The images or other third party material in this article are included in the article's Creative Commons license, unless indicated otherwise in a credit line to the material. If material is not included in the article's Creative Commons license and your intended use is not permitted by statutory regulation or exceeds the permitted use, you will need to obtain permission directly from the copyright holder. To view a copy of this license, visit http://creativecommons.org/ licenses/by/4.0/.

This is a U.S. government work and not under copyright protection in the U.S.; foreign copyright protection may apply 2021 